
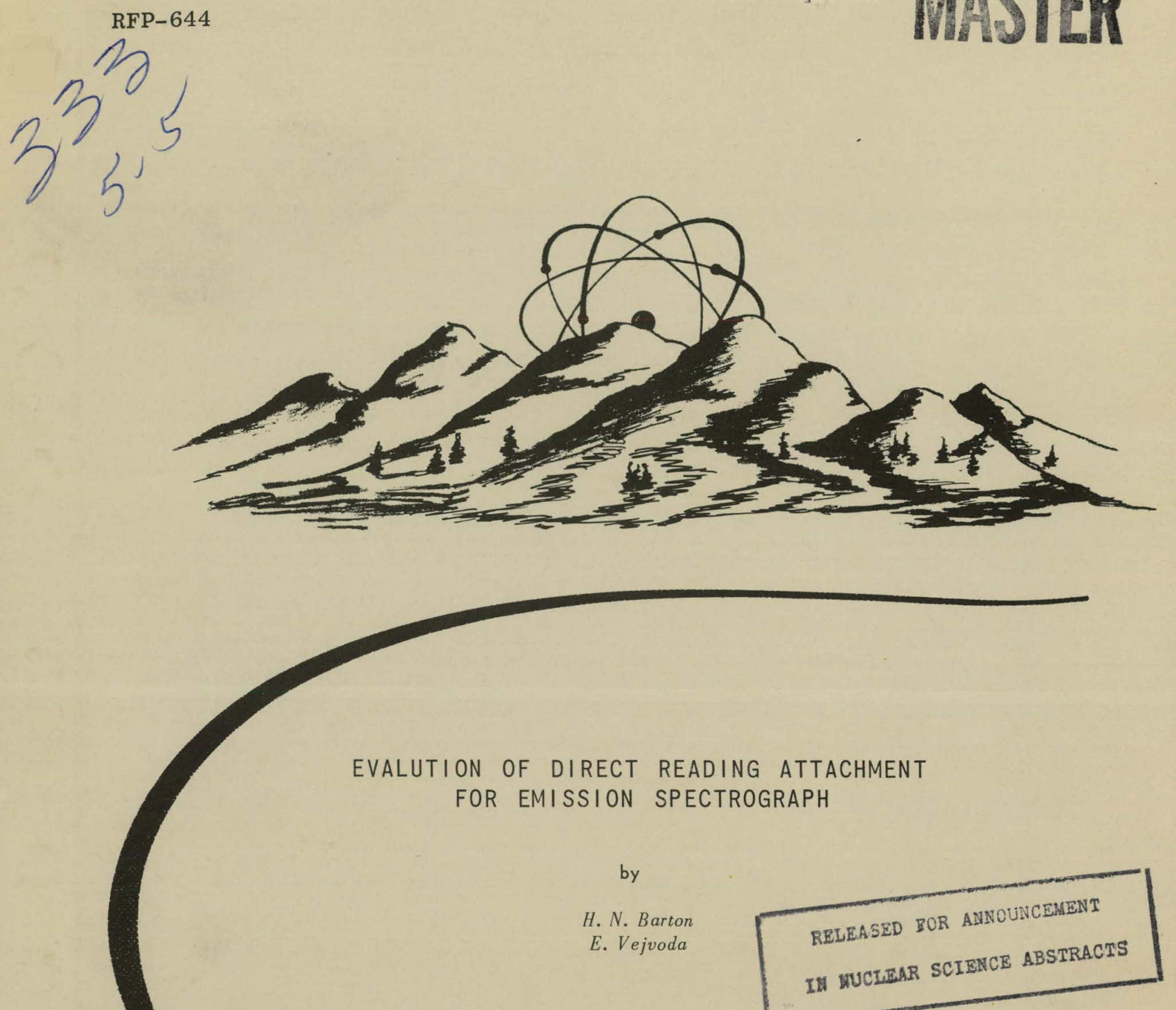


\section{DISCLAIMER}

This report was prepared as an account of work sponsored by an agency of the United States Government. Neither the United States Government nor any agency Thereof, nor any of their employees, makes any warranty, express or implied, or assumes any legal liability or responsibility for the accuracy, completeness, or usefulness of any information, apparatus, product, or process disclosed, or represents that its use would not infringe privately owned rights. Reference herein to any specific commercial product, process, or service by trade name, trademark, manufacturer, or otherwise does not necessarily constitute or imply its endorsement, recommendation, or favoring by the United States Government or any agency thereof. The views and opinions of authors expressed herein do not necessarily state or reflect those of the United States Government or any agency thereof. 


\section{DISCLAIMER}

Portions of this document may be illegible in electronic image products. Images are produced from the best available original document. 


\section{LEG A L NOTICE}

This report was prepared as an account of Government sponsored work. Neither the United States, nor the Commission, nor any person acting on behalf of the Commission:

A. Makes any warranty or representation, expressed or implied, with respect to the accuracy, completeness, or usefulness of the information contained in this report, or that the use of any information, apparatus, method, or process disclosed in this report may not infringe privately owned rights; or

B. Assumes any liabilities with respect to the use of, or for damages resulting from the use of any information, apparatus, method, or process disclosed in this report.

As used in the above, "person acting on behalf of the Commission" includes any employee or contractor of the Commission, or employee of such contractor, to the extent that such employee or contractor of the Commission, or employee of such contractor preparcs, disseminates, or provides access to, any information pursuant to his employment or contract with the Commission, or his employment with such contractor.

Printed in USA. Price $\$ 2$. Available from the Clearinghouse for Federal Scientific and Technical Information, National Bureau of Standards,

U. S. Department of Commerce, Springfield, Virginia 


\title{
EVALUATION OF DIRECT READING ATTACHMENT \\ FOR EMISSION SPECTROGRAPH
}

\section{by}

\author{
H. N. Barton \\ E. Vejvoda
}

\begin{abstract}
LEGAL NÖTICE
This report was prepared as an account of Government sponsored work. Neither the United States, nor the Commission, nor any person acting on behalf of the Commission:

A. Makes any warranty or represenlation, expressed or implicd, with respect to the arcinracy, completeness, or usefulness of the information contained in this report, or that the use of any information, apparatus, method, or process disclosid in this report may not infringe privately owned rights; or

B. Assumes any liabilitiles whth respect to the use of, or fur thmages fiviltung from tho use of any Information, apparatus, method, or process disclosed in this report.

As used in the above, "person acting on behalf of the Commission" includes any employee or contractor of the Commission, or employee of such contractor, to the extent that such employee or contractor of the Commission, or employee of such contractor prepares, disemintes or provides accese to, any information pursuant io his employment or com with the Commission, or hls employment with such contractor.
\end{abstract}

\author{
THE DOW CHEMICAL COMPANY \\ ROCKY FLATS DIVISION \\ P. O. BOX 888 \\ GOLDEN, COLORADO 80401 \\ U.S. ATOMIC ENERGY COMMISSION \\ CUN'LAL'H ATT(29-1)-1100
}




\begin{abstract}
A photoelectric recording (direct reading) attachment for a 3.4-meter Ebert emission spectrograph is described and evaluated. Relationships and constants describing excitation, photographic recording, photoelectric recording, and optical alignment are determined. Impurity analysis of $\mathrm{PuO}_{2}$ and $\mathrm{U}_{3} \mathrm{O}_{8}$ with direct reading by a carrier distillation method is described also.
\end{abstract}


Abstract . . . . . . . . . . . . . . . . . . . . . . . . . . ii

Summary

Introduction

Instrument Description

A. General

B. Exit Slits .

C. Alignment of Exit Optics

D. Entrance Slit

E. Optical Monitor.

F. Fatigue Light

G. Electronic Read-Out

Experimental

A. Photomultipiier Tübe

1. Sensitivity

2. Spectral Response

3.

Photographic-Photoelectric $\dot{i}$

4.

Photographic-Photoelectric

5. Effect of Dynode Voltage on Photoelectric Counts

7. Factors Affecting Photomultiplier Tube Reproducibility

8. Measured Dynode Voltage

B. Optical Alignment

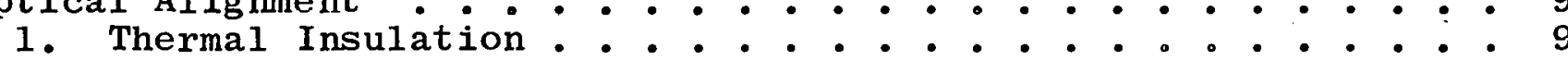

2. Displacement of Light by Refractor Plate... . . . . . . . 10

3. Deviation of Light by Prism . . . . . . . . . . . . . . . 10

4. LIne Profiles .. . . . . . . . . . . . . . . . . . . . . . . 11

5. Alignment of Exit Sits to Parallel Spectra Lines . . . . 11

6. Stability of Excitation . . . . . . . . . . . . . . . . 12

7. Vertical Displacement of Spectra . . . . . . . . . . . . 13

C. Electronic Read-Out . . . . . . . . . . . . . . . . . . . 13

1. Electronic Test Without Photomultiplier Tubes . . . . . . . 14

2. Linearity of Read-Out . . . . . . . ... . . . . . . . 14

3. Count Saturation . . . . . . . . . . . . . . . . . . . 14

4. Relationship of Counting Rate to Current . . . . . . . . . 14

5. Effect of Spark-Source Unit . . . . . . . . . . . . . . . . 15

6. Relationship of Counts to Voltage on Storage Capacitor . . 15

7. Time-Intensity Curves . . . . . . . . . . . . . . . . . 15

D. Spectrochemical Analysis . . . • . . . . . . . . . . . . . 16

1. Impurities in Solution Analysis . : . . . . . . . . . . . 16

2. Carrier Distillation Method of Impurities in $\mathrm{PuO}_{2}$. . . . 16

3. Carrier Distillation Method for Impurities in $\mathrm{U}_{3} \mathrm{O}_{8} \cdot \ldots . . .17$

Illustrations 


\section{ILLUSTRATIONS}

Figure

Page

1 Ebert Spectrograph and Associated Equipment . . . . . . . . . 20

2 Side Mounted Direct Reading Head . . . . . . . . . . . . . 20

3. Photomultiplier Tubes and Exit Slits Mounted on Focal Curve.. . 21

4 Exit Slit Assemblies with Prism and Mirrors for Diverting Light to Photomultiplier Tubes . . . . . . . . . . . . . . 21

5 Exit Slit Assembly • • . . . . . . . • • . . . . . . . . . 22

6. Entrance Slit Assembly . . . . . . . . . . . . . . . . . 22

7 Relationship of Optical Density of SA-1 Plate to Direct

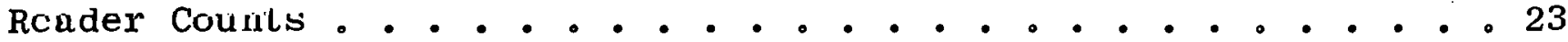

8 Relationship of Counting Rate to Dynode Voltage . . . . . . . . 23

9 Relationship of Dark Current to Dynode Voltage . . . . . . . . 24

10 Ratio of Fatigue Light Counts to Dark Current Counts as Function of Dynode Voltage . . . . . . . . . . . . . . . . 24

11 Relátionship of Dynode Voltage to Voltage Control Setting • •. 25

12 Refractor Plate Angle Required to Maintain optical

Alignment. Spectrograph Not Insulated . . . . . . . . . . . 25

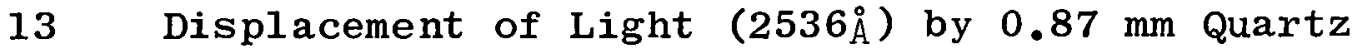

Refractor Plate. . . . . . . . . . . . . . . . . . . 26

14 Angular Deviation Produced by $30^{\circ}$ Quartz Prism . : . . . . . 26

15 Displacement at Focal Curve Produced by 300 Quartz Prism . . . 26

16 Profile of $2536 \AA$ Line, Hg Lamp $30 \mu$ Entrance slit, $50 \mu$ Exit Sl1t. . . . . . . . . . . . . . . . . . . . . 27

17 Profile of $\mathrm{Ge} 2651.18 \AA$ and $\mathrm{Ge} 2651.58 \AA \quad$. . . . . . . . . . . . . 27

18 Profile of Ga $2874.24 \AA \quad$. . . . . . . . . . . . . . . . . . . . . 28

19 Profile of Al $3092.71 \AA$. . . . . . . . . . . . . . . . . . . 28

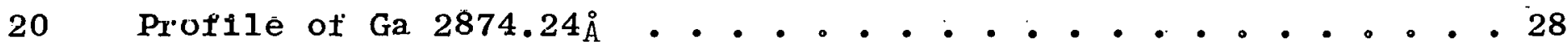

21 Apparent Line Width as Function of Misalignment Angle of Exit

Slit to Spectrum Line . ......................... 29

22 Phototube Current as Function of Misalignment Angle of Exit Slit to Jpectrum Line 。. . . . . . . . . . . . . . . . . . . 29

23 Time-Intensity Curve, Ten Percent FeO in Graphite, Direct

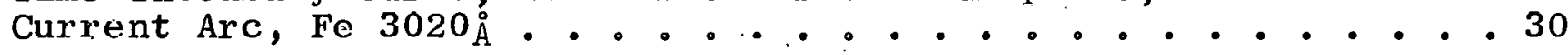

24 Time-Intensity Curve, Ten Percent FөO in AgCl, Direct Current

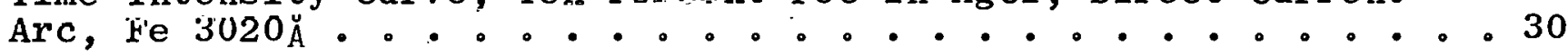

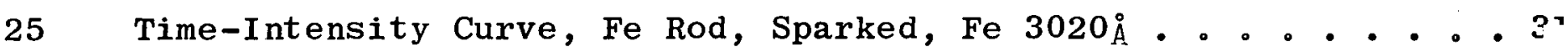

26 Time-Intensity Curve, Feo and Graphite Pellet, Sparked, Fe $3020 \AA$ 


\section{ILLUSTRATIONS (Concluded)}

Figure

Page

27 Time-Intensity Curve, Ferric Nitrate, Rotrode, Sparked, Fe $3020 \AA$ 。 . . . . . . . . . . . . . . . . . . . . . . . . 31

28 Time-Intensity Curve, Sparked, Fe $3020 \AA$ Electrodes Soaked in Ferric Nitrate Solution . . . . . . . . . . . . . . . . . 32

29 Vertical Displacement of Spectra as Function of Grating Angle . .32 30 Saturation Counts . . • . . . . . . . . . . . . . . 33

31 Direct Reader Counts as Function of Capacitor Voltage . . . . . 33

32 Time-Intensity Curve, 2UU p pm Fe 1n $\mathrm{PuO}_{2}$, NaF Carricr Dist111ation Method, Fe $3020 \AA$ - . - . • . . . . . . . $\because \because . .34$

33 Time-Intensity Curve, $50 \mathrm{ppm} \mathrm{Be}$ in $\mathrm{PuO}_{2}$, NaF Carrier

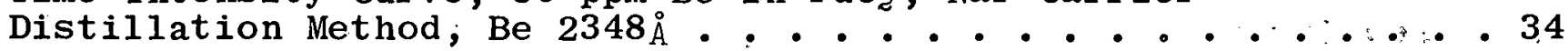

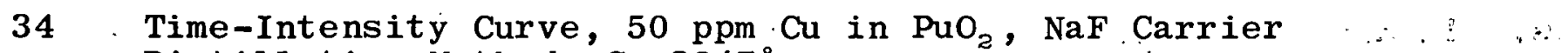

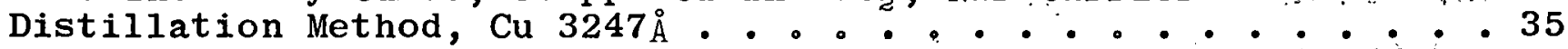

35 Working Curve, Solution Impurities . . . . . . . . . . . . 35

36 Working Curve, Impurities in Plutonium Dioxide, NaF Carrier Distillation Method . . . . . . . . . . . . . . . . . 36

37 Working Curves, Impurities in $\mathrm{U}_{3} \mathrm{O}_{8}$, Carrier Distillation...$\cdot 36$ Method 


\section{SUMMARY}

In addition to the obvious advantages of greater speed in direct reading as opposed to continuous spectral coverage of photographic recording, the folluwing comparative advantages have been determined:

Direct reading offers greater precision in measuring spectral line intensities. In measuring optimum intensities a relative standard deviation of \pm 1 percent was obtained by direct reading as compared with \pm 3 percent by photographic recording.

Photographic recording possesses greater sensitivity. The limit of detection by photographic recording is approximately one-tenth that of direct reading.

'lhe superior resolution of photographic rccording makes spectral interferencc of less siyniflcance than with direct reading. Photographic recording offers a working resolution as low as 10 microns as compared to 100 microns for direct reading.

Direct reading requires a higher degree of optical alignment. Interactions which have no significant effect on photographic recording can greatly affect direct reading results. 


\section{INTRODUCTION}

To increase the research and development capabilities in optical emission spectroscopy, a commercially-available photoelectric recording (direct reading) attachment was obtained from Jarre11-Ash. The direct reading attachment was designed to be compatible with the Jarre11-Ash Mark III 3.4-meter Ebert photographic spectrograph and was installed with the aid of a Jarre11-Ash service engineer.

The spectrograph possesses a high degree of versatility, incorporating provisions for operation in either direct reading or photographic modes. Elements to be recorded photoelectrically may be selected by the operator by appropriate placement of exit slits and photomultiplier tubes along the focal curve.

To meet demands for an increased number of analyses and greater precision, the Plutonium Analytical Laboratory has purchased a direct reading spectrometer containing 34 fixed exit slits and photomultiplier tubes and an additional 18 exit slits for future expansion. The Ebert convertible direct reading spectrograph was used to determine performance criteria for the Analytical Laboratory instrument prior to its purchase and to evaluate present photographic methods for their adaptability to direct reading techniques.

Before starting such a study, it was necessary to become familiar with direct reading techniques. This report summarizes the results from these familiarization studies.

\section{INSTRUMENT DESCR IPTION}

A. GENERAL

A portion of the Jarrell-Ash Mark III 3.4-meter Ebert spectrograph with direct reader attachment and associated equipment is shown in Figure. 1. The direct reading head containing exit slit assemblies and photomultiplier tubes is shown at the left mounted to the side of the spectrograph. The read-out console, printer, and recorder are shown in the right portion of the picture. 
The system is readily convertible from photographic to direct reading by the lowering of a mirror extending diagonally across the spectrograph into the light path. This mirror reflects the light to the side-mounted direct reading head.

\section{B. EXIT SLITS}

Views of the arrangement of exit slits and photomultiplier tubes without the light-tight cloth cover and protective metal cover are shown in Figures 2 and 3 . Exit slit assemblies containing a vertical slit 50 microns wide are attached to the focal curve. Photomultiplier tubes are positioned behind their respective slit assemblies.

Where two or more analytical lines are closer together than photomultiplier tubes can be positioned, the light, after passage through the exit slit, can be diverted by a mirror or prism to the photomultiplier tube. A close-up view of some arrangements of mirrors and prisms on exit slit assemblies is shown in Figure 4.

\section{ALIGNMENT OF EXIT OPTICS}

Alignment of an individual exit slit is accomplished by movement of the exit slit assembly along the focal curve untill coincidence of the exit slit and the desired emission spectrum line is achieved. Thia is usually determined photographically by mounting a piece of film on the exit slit assembly, recording the spectra of interest, and marking the slit position with light through the si.t from the rear.

Final precise alignment is accomplished by displacement of the spectrum line with an individual quartz refractor plate mounted in front of the oxit olit. The spectriul line may ve displaced the desired distance to the side, from its original path, by rotation of the refractor plate about its vertical axis, to the appropriate position. Inten-sity variations of the light through the exit slit arc normally recorded photoelectrically during this final alignment. The refractor plate is shown in Figure 5 .

The exit slit is made parallel to the emission line by means of a cam arrangement of the slit assembly. 


\section{ENTRANCE SLIT}

A quartz refractor plate is located inside the entrance slit housing (shown in Figure 6). The refractor plate can be rotated about its vertical axis to shift the entire spectrum slightly in a horizontal plane. A scale below the housing indicates the angle between the normal to the refractor plate and the optic axis of the instrument. Immediately in front of the entrance slit is a mercury lamp (shown in Figure 6). This lamp is automatically withdrawn during an exposure.

\section{E. OPTICAL MONITOR}

The mercury lamp at the entrance slit provides a stable source of mercury emission line spectra to permit detection of any change in optical alignment. As changing environmental conditions (temperature and airflow) result in a shift of spectral lines off the exit slits, the misalignment is detected by a lower than normal phototube current from the phototube receiving the light of a mercury line. The refractor plate at the entrance slit can then be rotated to bring the mercury line back to its proper alignment.. This adjustment also brings all other lines back into alignment on their respective exit slits.

\section{F. FATIGUE LIGHT}

The fatigue light system consists of a Lucite ${ }^{\circledR *}$ rod illuminated at each end by a tungsten lamp. This rod is located in front of the exit slits and provides some illumination to the photomultiplier tubes. One of its functions is to provide a continuous low-level illumination to improve phototube stability. A second function is to provide a light source for testing phototubes and read-out systems which is independent of spectrographic alignment. The fatigue light is turned off automatically during an analytical exposure.

\section{r. ELECTRONIC READ-OUT}

The read-out system is a Jarrell-Ash Sequential Atomcounter Electronic System with power supply and read-out channels for 10 
analytical lines. The unit has the capability of expansion to 30 analytical lines. During an analytical exposure the photocurrent from each phototube is stored on a storage capacitor. Following the exposure, the voltage on these capacitors is sequentially measured and presented on a 4-digit display tube scaler. The read-out can also be recorded by a Hewlett-Packard Model 560A digital recorder.

\section{EXPER IMENTAL}

A. PHOTOMULTIPLIER TUBES

1. Sensitivity

To determine relative sensitivities, the 1 P28 photomultiplier tubes were given equal exposures to the fatigue light for 30 seconds with a dynode voltage control setting of 50 (850 volts). Dark-current values were also obtajined for each tubo undcr the same conditions. The data obtained for 20 repetitive exposures, for each tube, are summarized in Table I.

From the data presented in Table $I$ it is apparent that tube selection will critically affect analyticai results. The reproducibility for the 15 tubes studied varied by a factor of four and the sensitivity varied by a factor of five. The dark currcnt differed by a factor of three all a half. The signal to darkcurrent ratio varied by more than a factor of six.

No one tube possessed all the desirable characteristics of low dark current, high sensitivity, high signal to dark-current ratio, and good reproducibility. Tube 1512 appears to best meet these performance criteria.

The variations in photomultiplier tube characteristics provide for selective use. If high precision within a limited impurity concentration range is required, high reproducibility and a high signal-to-background ratio are tube characteristics most desired for the application. If a wide impurity concentration range must be covered, a tube with less sensitivity should be used to permit coverage with a single analytical curve. The 
TABLE I

CHARACTERISTICS OF INDIVIDUAL 1 P28 PHOTOMULTIPLIER TUBES

\begin{tabular}{rrrrr} 
Tube No. & $\begin{array}{c}\text { Fatigue Light } \\
\text { Counts* }\end{array}$ & $\begin{array}{c}\text { RSD** } \\
(\%)\end{array}$ & $\begin{array}{c}\text { Dark-Current } \\
\text { Counts }\end{array}$ & $\begin{array}{c}\text { Fatigue Light/ } \\
\text { Dark Current }\end{array}$ \\
\cline { 2 - 4 } 782 & 1218 & 0.25 & 94 & 12.96 \\
787 & 1604 & 0.34 & 96 & 16.70 \\
1001 & 1963 & 0.38 & 103 & 19.05 \\
1002 & 1160 & 0.33 & 228 & 5.09 \\
1003 & 1720 & 0.38 & 174 & 9.89 \\
1004 & 2427 & 0.40 & 287 & 8.46 \\
1005 & 1069 & 0.30 & 90 & 11.88 \\
1444 & 4308 & 0.33 & 175 & 24.61 \\
1453 & 4775 & 0.40 & 141 & 39.85 \\
1467 & 4410 & 0.46 & 315 & 14.00 \\
1473 & 4338 & 0.30 & 188 & 23.07 \\
1492 & 3300 & 0.27 & 125 & 26.40 \\
1498 & 3084 & 0.32 & 108 & 18.55 \\
1500 & 2226 & 0.55 & 148 & 15.03 \\
1512 & 5403 & 0.13 & 197 & 27.86 \\
Average & 2867 & 0.34 & 165 & 17.83 \\
Low & 1069 & 0.13 & 90 & 5.09 \\
High & 5403 & 0.55 & 315 & 33.85
\end{tabular}

NOTES :

* Average of 20 determinations.

** Relative standard deviation defined as RSD = :

standard deviation/mean x 100 .

analytical requirements will, therefore, govern photomultiplier tube selection.

2. Spectral Response

To determine if 1 P28 photomultiplier tubes differed in spectral response, counts in response to exposure to various emission lines of a mercury lamp were determined for individual photomultiplier tubes. The count ratios of pairs of photomultiplier tubes were calculated.' A change in count ratio with wavelength would indicate photomultiplier tubes differed in spectral response.

An example of a significant trend in count ratios for two tubes is shown in Table II. The trend, however, is shown to be a function of grating angle of incidence rather than wavelength 


\section{COUNT RATIOS OF 1 P28 PHOTOMULTIPLIER PAIR FOR MERCURY EMISSION LINES}

\begin{tabular}{|c|c|c|}
\hline $\begin{array}{r}\text { Wavelength } \\
(\AA)\end{array}$ & $\begin{array}{c}\text { Grating Angle } \\
(0)\end{array}$ & $\begin{array}{lll}\text { Counts } & \text { Tube } & \mathbf{7 8 2} \\
\text { Counts } & \text { Tube } & 1492 \\
\end{array}$ \\
\hline $\begin{array}{l}2536.52 \\
2967.28 \\
3131.55 \\
3650.15 \\
4046.56 \\
4358.35 \\
2536.52 * \\
5460.74\end{array}$ & $\begin{array}{r}9.87 \\
11.33 \\
11.89 \\
13.70 \\
15.08 \\
16.17 \\
18.69 \\
20.07\end{array}$ & $\begin{array}{l}0.624 \\
0.646 \\
0.680 \\
0.714 \\
0.760 \\
0.802 \\
0.878 \\
0.866\end{array}$ \\
\hline
\end{tabular}

* Second order.

by the intensity ratio for the second order of the $2536.52 \AA$ line. The change in count ratios for pairs of photomultiplier tubes is believed to be due primarily to a vertical displacement of the spectra with change in grating angle of incidence as described on page 13. Different areas of the photocathodes are thus being compared for varying grating angles and it is not possible to attribute the difference to variations in spectral respunse.

3. Photographic-Photoelectric Intensity Relationship

The relationship of counts obtained photoelectrically to spectral line density recorded photographically was established. This permitted predictions of the applicability of photographic recorded analytical methods to direct reading. This relationship, using the Hg $2536 \AA$ line from a mercury lamp source is shown in Figure 7. Calculations using the relationship shown in Figure 7 should take into consideration the differences in individual photomultiplier tubes since the relationship shown is valid only for the individual photomultiplier tube.

Photoelectric conditions were: 10-micron $x$ 5-millimeter entrance slit, 50-micron exit slit, 1 P28 photomultiplier tube No. 782, an a dynode voltage control setting of 50 ( 850 volts). 
Photographic conditions were: 10-micron entrance slit, Eastman Kodak SA-1 plate, 5-minute development in Kodak D-19 at $18.5^{\circ} \mathrm{C}$, and a 5-micron microphotometer slit.

The usable read-out count range covered by photoelectric recording with 1 P28 photomultiplier tubes is approximately 100 to 10,000 counts. This represents an intensity factor of 100 . Assuming a usable photographic density range of 0.1 to 2.0; an intensity factor of about 30 may be covered with SA-1 plates. This range can be increased, however, by use of a different photographic emulsion or photometric equipment capable of covering a greater density range.

4. Photographic-Photoelectric Limits of Detection

A comparison of limits of detection using the $2967.28 \AA$ line of a mercury lamp showed photographic recording possessed significantly more sensitivity than direct reading. The limit of detection with SA-1 plate was 10.5 percent of the limit of detection using a typical 1 P28 photomultiplier tube. The limit of detection for direct reading was taken as that intensity which exceeded the mean background by three standard deviations. The limit of detection for photographic recording was taken as that intensity which produced a photographic density of 0.0155 (96.5 percent transmittance).

Photoelectric conditions were: 30-micron x 7-mililimeter entrance slit, 50-micron exit slit, 1 P28 photomultiplier tube No. 782 , and a dynode voltage control setting of 110 (1430 volts).

Photographic conditions were: 30-micron entrance slit, Eastman Kodak SA-1 plate, 5-minute development in Kodak D-19 at $18.5^{\circ} \mathrm{C}$.

\section{Photographic-Photoelectric Precision}

Precision of measuring line intensities of a mercury lamp were determined for both photographic and direct reading in the optimum measuring ranges of each. The relative standard deviation as determined by 20 determinations was \pm 0.9 percent for direct reading and \pm 3.2 percent for photographic recording. 
Direct reading measurements were made with a voltage control setting of 50 (850 volts) using 1 P28 tube No. 782. Mean counts wer 3450. Photographic recording was with SA-1 plate. with a mean transmittance of 9.5 percent. Line densities were determined using a Jarrell-Ash 24-300 recording microphotometer.

6. Effect of Dynode Voltage on Photoelectric Counts

The response of a photomultiplier tube to light of constant intensity may be increased by about a factor of ten by increasing the dynode voltage control from minimum to maximum value. This relationship is shown in Figure 8. The corresponding increase in dark current is shown in Figure 9. The ratio of counts-response-towhite-light to counts-response-for-dark-current, as a function of dynode voltage, is shown in Figure 10 .

7. Factors Affecting Photomultiplier Tube Reproducibility The reproducibility of measuring white light varies with dynode voltage. The relative standard deviation of direct-reader scaler counts in measuring white light, with 1 P28 photomultiplier tube No. 1453, at a dynode voltage control setting of 30 , was \pm 0.37 percent; at a setting of 50 , this increased to \pm 0.40 percent, and at a setting of 70 it was \pm 1.37 percent.

The reproducibility also varied with phototube warm-up time. After a warm-up time of 1 minute, the relative standard deviation was \pm 1.94 percent; after 10 minutes, it was \pm 0.40 percent; and after 16 hours, it decreased to ${ }_{ \pm} 0.28$ percent.

The value of the fatigue light in giving increased reproducibility was investigated by determining the variance in measuring both relatively low light intensities from the fatigue light and. high intensities from the $2536 \AA$ line of a mercury lamp after exposure of the photomultiplier tubes to the fatigue iight for 24 hours and after being in total darkness 24 hours.

Use of the fatigue light gave better reproducibility in the case of only two of six photomultiplier tubes tested for measuring 
RFP-644

white light of the fatigue light. A slightly lower variance for measurements of the $2536 \AA$ mercury line was obtained with use of the fatigue light. However, application of the $F$ test for equality of variances showed no significant difference at the 95 percent confidence level. It is concluded, therefore, that the fatigue light is of little or no value in increasing reproducibility.

8. Measured Dy node Voltage

The measured dynode voltage as a function of dynode voltage control setting is shown in Figure 11 .

B. OPTICAL ALIGNMENT

1. Thermal Insulation

Considerable difficulty was experienced with the instability of optical alignment. Changing environmental conditions caused the entire spectrum to move sideways in a random manner, thus moving analytical lines off their respective exit slits.

Correct alignment could usually be maintained by means of a rotatable refractor plate at the spectrograph entrance slit to adjust the $2536 \AA$ line from a mercury lamp back onto its exit slit. Since light of all wavelengths passes through the.same refractor plate, adjusting the $2536 \AA$ mercury monitor line onto its exit slit also adjusts the analytical lines onto their exit slits.

This sytem was not satisfactory since the rapid change in alignment necessitated frequent determination of its correctness. The angular setting of the entrance refractor plate required to maintain alignment of the mercury light monitor on 2-typical days is shown in Figure 12 .

Attempts to relate the misalignment to changing room temperature or air pressure were unsuccessful. The changes in alignment were related most closely to airflow near the spectrograph. Changes in conditions affecting airflow produced rapid changes in alignment. 
The alignment stability problem was remedied by insulating the spectrograph with 2-inch sheets of flexible polyurethane foam. After insulation, adjustments of the refractor plate seldom exceeded a degree or two in several hours to correct for the movement of the monitor line.

2. Displacement of Light by Refractor Plate

The displacement of light by a refractor plate is nearly a linear function of the angle of incidence for angles of incidence less than 30 degrees. The displacement produced by a 0.87-mm quartz refractor plate is shown in Figure 13 .

Displacement by a refractor plate may be calculated from the formula

$$
\mathrm{d}=\mathrm{t} \sin \Phi\left(1-\frac{\mathrm{n} \cos \Phi}{\mathrm{n}^{\prime} \cos \Phi^{\prime}}\right)^{*}
$$

where $d$ is displacement, $t$ is refractor plate thickness, $\Phi$ is angle of incidence, $\Phi^{\prime}$ is angle of refraction, $n$ is the refractive index of air, and $n^{\prime}$ is the refractive index of the refractor plate.

3. Deviation of Light by Prism

The angular deviation of light produced by the prism fares forming a 30 angle of a 30-60-900 triangular base quartz prism is shown in Figure 14. Angular deviation is considered to be the total change in direction of the light beam and angle of incidence is the angle formed by the light and the normal to the prism face.

The linear displacement of an analytical line along the focal curve ie dopendint both upon the angular deviatiull and the distance from the focal curve to the point of intersection of the light with the prism tace. Since with the Jarrell-Ash exit slit assemblies, rotation of the refractor plate moves this point of intersection, the displacement of the light along the focal curve is a complex function of the angle of incidence. This relationship is shown in Figure 15.

\footnotetext{
* Jenkins, F. A., and White, H. E., Fundamentals of Optics, New York, McGraw Hill Book Co., 1950.
} 
4. Line Profiles

A profile of the $2536 \AA$ line from a mercury lamp is shown in Figure 16. Scanning was done with the entrance refractor plate using a 30-micron entrance and 50-micron exit slit. A line width at one-half peak height of 117 microns was obtained. The calcu-. lated line width at one-half peak height (with no allowance for actual line width) is 50 microns for the slit widths used.

Profiles of lines originating from elements excited in a d-c arc are shown in Figures 17, 18, and 19. Oxides of the elements were diluted in graphite and the intensity measured for a 60-second exposure for each point determined.

While this method of integrating counts to profile analytical lines gives rough profiles, it is not accurate enough for precise adjustments of exit slits as may be seen from Figure 20 where a number of points only poorly define the profile of the line.

\section{Alignment of Exit Slits to Parallel Spectra Lines}

Exit slits are made parallel to spectra line images at the focal plane by rotating the exit slit about an axis through the slit in the direction of the light path. Misalignment in this aspect adversely affects the resolution attained. Figure 21 shows the line widths at one-half peak height for the $2536 \AA$ line of a mercury lamp using a 30-micron x 7-millimeter entrance slit and a 50-micron exit slit for varying angles of misalignment. Photomultiplier tube current is also adversely affected as shown in Figure 22 using the same entrance and exit slits as for Figure 21.

While it is difficult to achieve the required degree of parallelism by comparison of photographic images of slit and analytical line, this can be observed electronically.. The grating angle of incidence is changed to bring an emission line of the mercury lamp onto the exit slit of interest and the exit slit rotated to give minimum peak wi.dth. No change in the best alignment angle was observed over a grating angle of incidence range of 10 degrees. 
6. Stability of Excitation

The need for a stable source of emission spectra of various elements to permit adjusting exit slits onto the desired analytical lines led to an investigation of various excitation sources and sample forms.

Figures 23-28 are time-intensity curves showing the stability of various sources. To be suitable for fine alignment of the exit slits, a source must be stable long enough to permit the making of adjustments and observation of their effects.

As is apparent from Figure 23, $d-c$ arc of Iron oxide diluted in graphite is only suitable for gross adjustment of the exit slit due to the extreme intensity variation of the iron spectra. The first peak, from 0 to 40 seconds, represents a distillation process andlittle of the crater is consuned during this period.

The series of peaks from 1 to. 2-1/2 minutes shows the variation in intensity as the arc rotates around the electrode rim during consumption of the electrode crater. At 2-1/2 minutes the crater is completely consumed and the emission of the iron spectrum is complete.

Figure 24 shows the intensity of the iron spectrum from a d-c arc of iron oxide in silver chloride. The intensity minimum at 1 minute coincided with the disappearance of silver from the arc. While in the case of iron the addition of a carrier did not improve the stability of the arc, in the case of beryllium the addition of silver chloride was of definite value in stabilizing the arc.

Alternating-current arcs prolonged the emission of spectra of lower intensity but gave no improvement in stability.

Spark sources gave spectra of relatively uniform intensity over a period of several minutes. The spark parameters which gave the greatest stability were a capacitance of $0.0150 \mu f$ (the largest capacitance obtainable with the NSL 100-1 source unit used) and 
zero inductance. The adjustment of the number of discharges per second with the auxiliary gap appeared to have little effect on the stability of emission.

As is shown in Figure 25, if metal electrodes of the desired element are available, the spark spectra are sufficiently stable for alignment purposes. Since all elements of interest were not available as self electrodes, investigation of special sample preparation techniques was undertaken.

As shown in Figure 26, spark excitation of a pellet prepared from iron oxide and graphite did not give stable emission.

Figure 27 shows the intensity stability obtained from a spark discharge using a rotrode and ferric nitrate solution. The stability is intermediate between that obtained from the pellet and that from the metalic electrode.

Figure 28 shows the stable emission obtained from sparking two graphite flat-top electrodes which had been soaked 2 days in a concentrated ferric nitrate solution and air dried. This technique has been used to obtain stable emission spectra for numerous other elements.

7. Vertical Displacement of Spectra Spectra were found to be displaced vertically as a function of grating angle of incidence. The downward displacement of spectra from the 30,000 line per inch grating is shown in Figure 29. While of little concern with photographic recording, displacements of the magnitude shown ( $t i 1 t$ of spectrum is less than $1 \mathrm{~mm}$ on a 10-inch plate) can shift spectra above or below exit slits unless corrected.

\section{ELECTRONIC READ-OUT}

The linearity and the reproducibility of the electronic read-out system was investigated by using a built-in test system (which is independent of photomultiplier tubes) and by exposure of the photomultiplier tubes to light of uniform intensity. 
1. Electronic Test Without Photomultiplier Tubes

The purpose of this test circuit is to test the reproducibility of the electronic read-out components. A fixed charge was placed on each of the channel storage capacitors and measured. The reproducibility for 20 determinations per channel is indicated in Table III.

TABLE II I

REPRODUCIBILITY OF ELECTRICAL COMPONENTS

\begin{tabular}{ccc} 
Channel & & Mean Counts \\
\cline { 1 - 1 } Test & & 3112 \\
1 & & 3097 \\
2 & & 3159 \\
3 & & 3050 \\
4 & & 3081 \\
5 & 3125 \\
6 & 3057 \\
7 & 3085 \\
8 & & 3108 \\
9 & 3116 \\
10 & 3078
\end{tabular}

\begin{tabular}{c} 
Counts Std. Dev. \\
\hline 1.395 \\
1.235 \\
1.147 \\
1.822 \\
1.277 \\
0.889 \\
1.051 \\
1.155 \\
1.100 \\
1.170 \\
0.859
\end{tabular}

Rel. Std. Dev. $(\%)$

0.045

0.040

0.036

0.060

0.041

0.029

0.034

0.037

0.035

0.038

0.028

2. Linearity of Read-Out

The linearity of counts to exposure was investigated by varying the exposure by means of time, slit height, and slit width. All showed a slight deviation from linearity for expnsures giving counts in excess of 5000 .

3. Count Saturation

High intensity exposures can exceed the capability of the readout system. The saturation counts (the number of counts which cannot be exceeded by increased exposure) is shown in Figure 30 as a function of voltage control setting.

4. Relationship of Counting Rate to Current

The relationship of counts per second of exposure recorded on the digital voltmeter, to amperes phototube current, is 8000 counts per second per microampere. 
5. Effect of Spark-Source Unit

In order to determine the effect of the spectrographic sparksource unit on the operation of the read-out system, reproducibility of two channels in measuring white light with and without the source unit in operation was determined.

The data in Table IV indicates that the source unit has no significant effect on the reproducibility of the read-out system.

TABLE IV

EFFECT OF SPARK-SOURCE UNIT ON ELECTRONIC READ-OUT

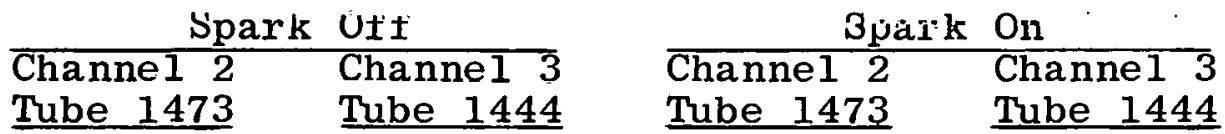

$\begin{array}{lllll}\text { Mean Counts } & 1339 & 822 & 1337 & 822\end{array}$

Counts

St. Dev.

$3.7 \quad 3.0$

3.5

2.5

6. Relationship of Counts to Voltage on Storage Capacitor

The relationship of direct-reader scaler counts to actual voltage on channel storage capacitors is shown in Figure 31.

7. Time-Intensity Curves

The current from an individual photomultiplier tube may be used to drive a recorder and give an instantaneous measure of the intensity of an analytical line as sample excitation proceeds.

Time-intensity curves showing the distillation of iron, beryllium, and copper from plutonium dioxide by a carrier distillation method* are shown in Figures 32,33 , and 34 . The rapid rise in intensity for copper and iron at approximately $2-1 / 2$ minutes is due to the excitation of the plutonium spectrum. The beryllium curve does not show this effect since the spectral region near the Be 2348 line is relatively free from plutonium interference.

* Johnson, A. J., and Vejvoda, E., Sodium Fluoride as a Spectroscopic Carrier for Plu+nnium Metal Analysis, The Dow Cliemicul Cümpany, Rocky Flats Divicion, April 20, 19.59: RFP-143. 
Analytical curves were prepared for the analysis of a number of elements by three methods: (1) analysis of impurities in solution, (2) a carrier distillation method for impurities in plutonium dioxide, and (3) a carrier distillation method for impurities in uranium oxide.

1. Impurities in Solution Analysis

Figure 35 shows the analytical working curves for the analysis of aluminum, copper, iron, manganese, and nickel in solution using cobalt as an internal standard. Fifty micrograms of cobalt in solution are added to a water-proofed ${ }^{\circ}$ UCP 4925 electrode and dried. Fifty microliters of solution to be analyzed are added to the electrode and dried. The sample residue is excited in a 3-ampere a-c arc for 30 seconds. Dark-current counts were subtracted from the gross counts for all elements.

2. Carrier Distillation Method of Impurities in $\mathrm{PuO}_{2}$

Figure 36 shows the analytical curves obtained for the analysis of aluminum, copper, magnesium, manganese, and $t$ in lmpurities in plutoniull diuxide by the sodium fluoride carrier method. No corrections were made for dark current. Since different photomulti= plier tubes were used having diffcrent dynode vullages, no collclusions can be made as to relative intensities of the various lines used.

The reproducibility of various carriers and internal standards for the carrier distillation of plutonium dioxide is shown in Table $V$. None of the carriers and internal standards investigated gave a significant improvement over the 5 percent sodium fluoride no-internal-standard method.

\section{TABLE V}

PERCENT REL. STD. DEV, FOR CARRIER DISTILLATION METHODS

Internal

\begin{tabular}{|c|c|c|c|c|c|c|}
\hline Carrier & Standard & $\mathrm{Mn}$ & $\mathrm{Si}$ & $\mathrm{Fe}$ & $\mathrm{Al}$ & $\mathrm{Ni}$ \\
\hline $\mathrm{Ga}_{2} \mathrm{O}_{3}$ & None & 9.31 & 9.52 & 11.53 & -- & 13.49 \\
\hline $\mathrm{Ga}_{2} \mathrm{O}_{3}$ & $\mathrm{Co}_{2} \mathrm{O}_{3}$ & 9.15 & 6.03 & $9.8 E$ & - & 7.48 \\
\hline $\mathrm{NaF}$ & None & 5.83 & 5.39 & 9.04 & 14.16 & 12.91 \\
\hline
\end{tabular}


TABLE V (concluded)

PERCENT REL. STD. DEV. FOR CARRIER DISTILLATION METHODS

\section{Internal}

Carrier Standard

$\mathrm{NaF}$

$\mathrm{NaF}$

$\mathrm{Co}_{2} \mathrm{O}$

$\mathrm{GeO}_{2}$

$\mathrm{Mn}$

14.90

$\mathrm{Si}$

Fe

13.10

10.90

A1

$\frac{\mathrm{Ni}}{9.80}$
17.50

Triple

Carrier*

None

10.80

5.80

-- .-

6.20

13.93

Tiriple

Carrier*

$$
\mathrm{Co}_{2} \mathrm{O}_{3}
$$

15.76

$7.36 \quad 15.91$

$-$

8.05

* Triple carrier is 5 percent $\mathrm{Ga}_{2} \mathrm{O}_{3}, 0.05$ percent $\mathrm{NaF}$, 0.5 percent $\mathrm{BaF}_{2}$.

3. Carrier Distillation Method for Impurities in $\mathrm{U}_{\mathbf{3}} \mathrm{O}_{\mathbf{8}}$

Figure 37 shows the analytical curves obtained for aluminum, boron, copper, iron, magnesium, silicon, and tin impurities in $\mathrm{U}_{3} \mathrm{O}_{8} \cdot$ The, carrier used was a mixture of five parts silver chloride, two parts gallium sesquioxide, and one part sodium fluoride. No corrections were made for dark current. 
RFP-644 


\section{ILLUSTRATIONS}




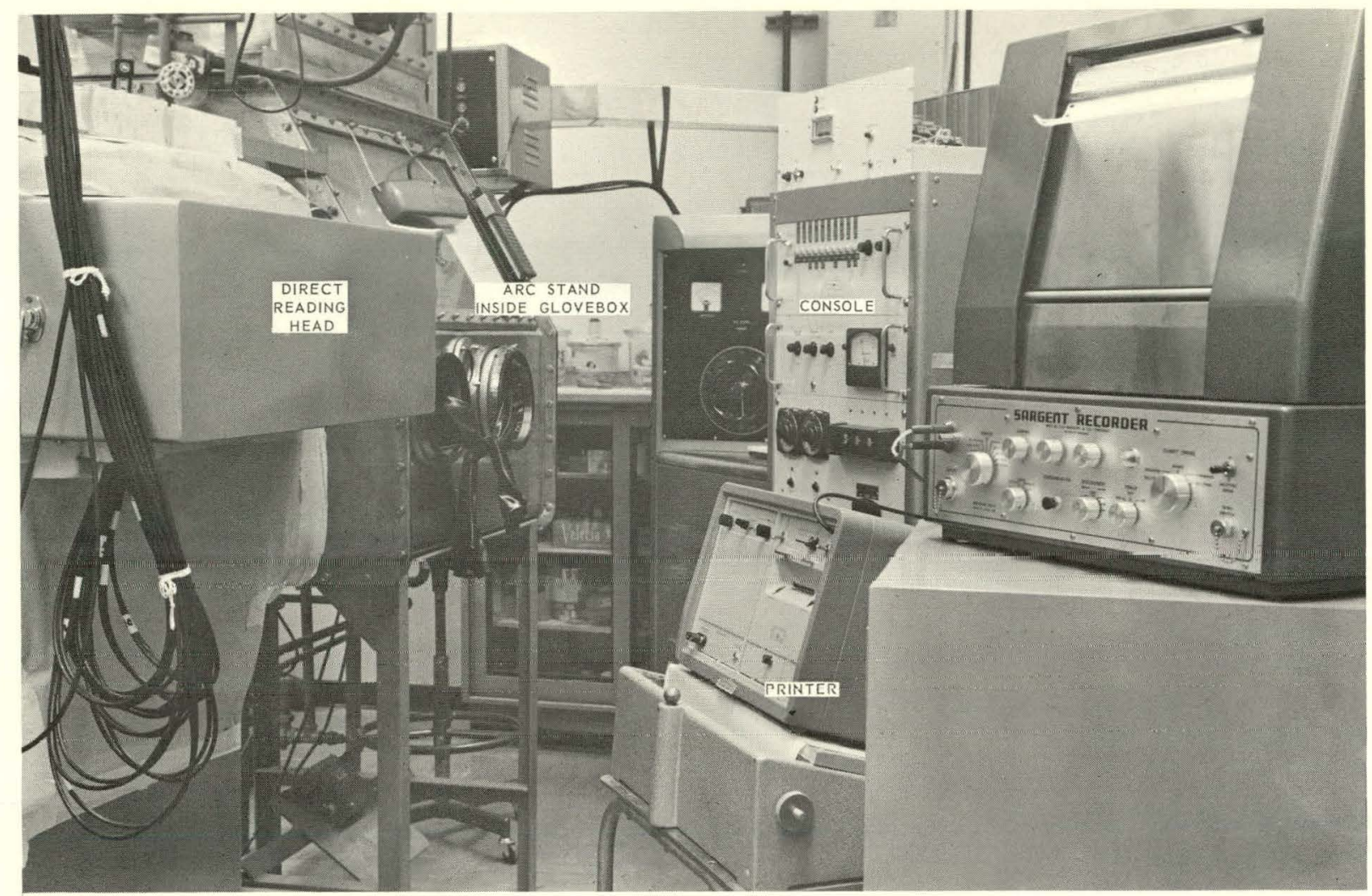

Figure 1 - Ebert Spectrograph and Associated Equipment

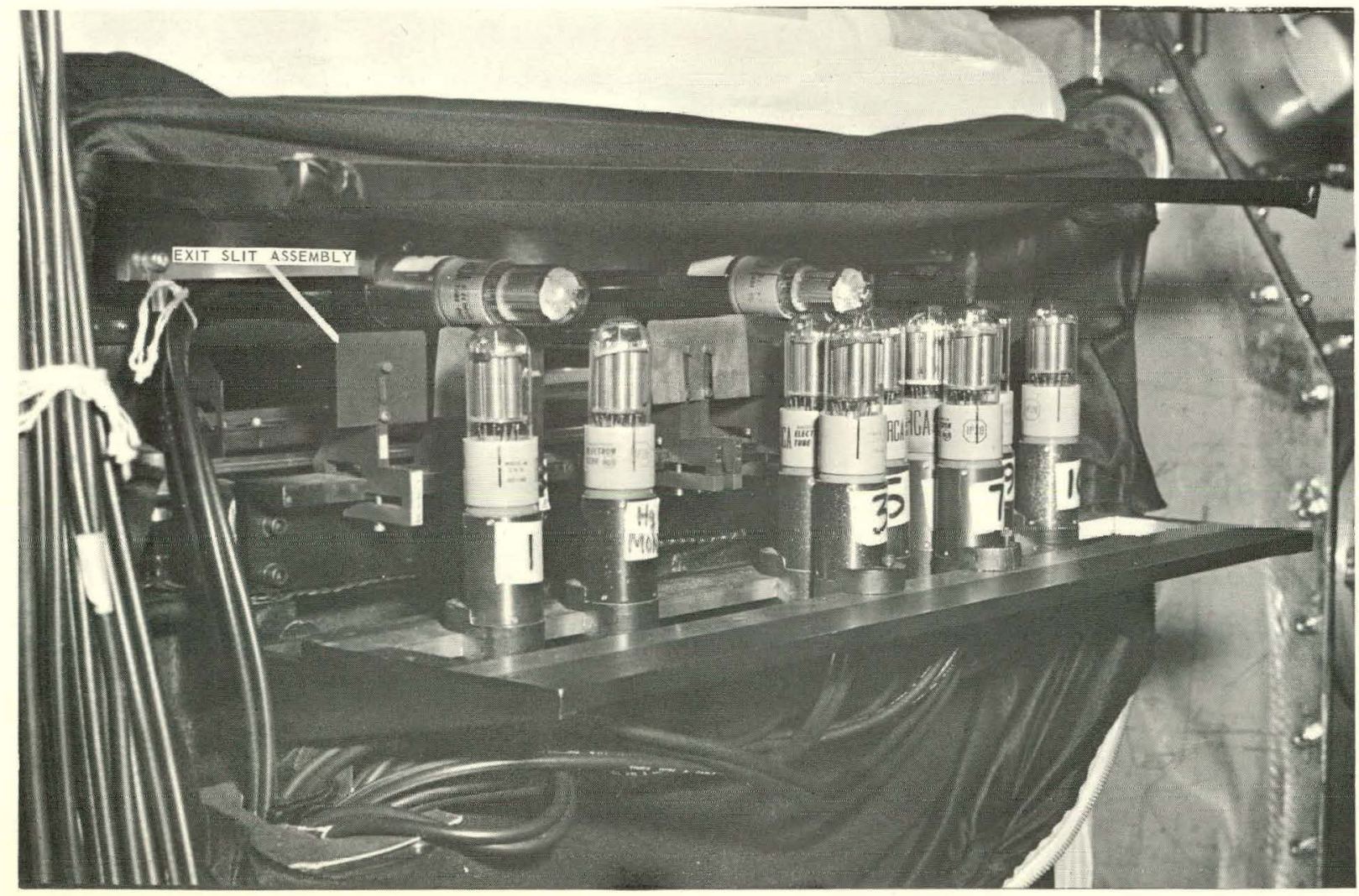




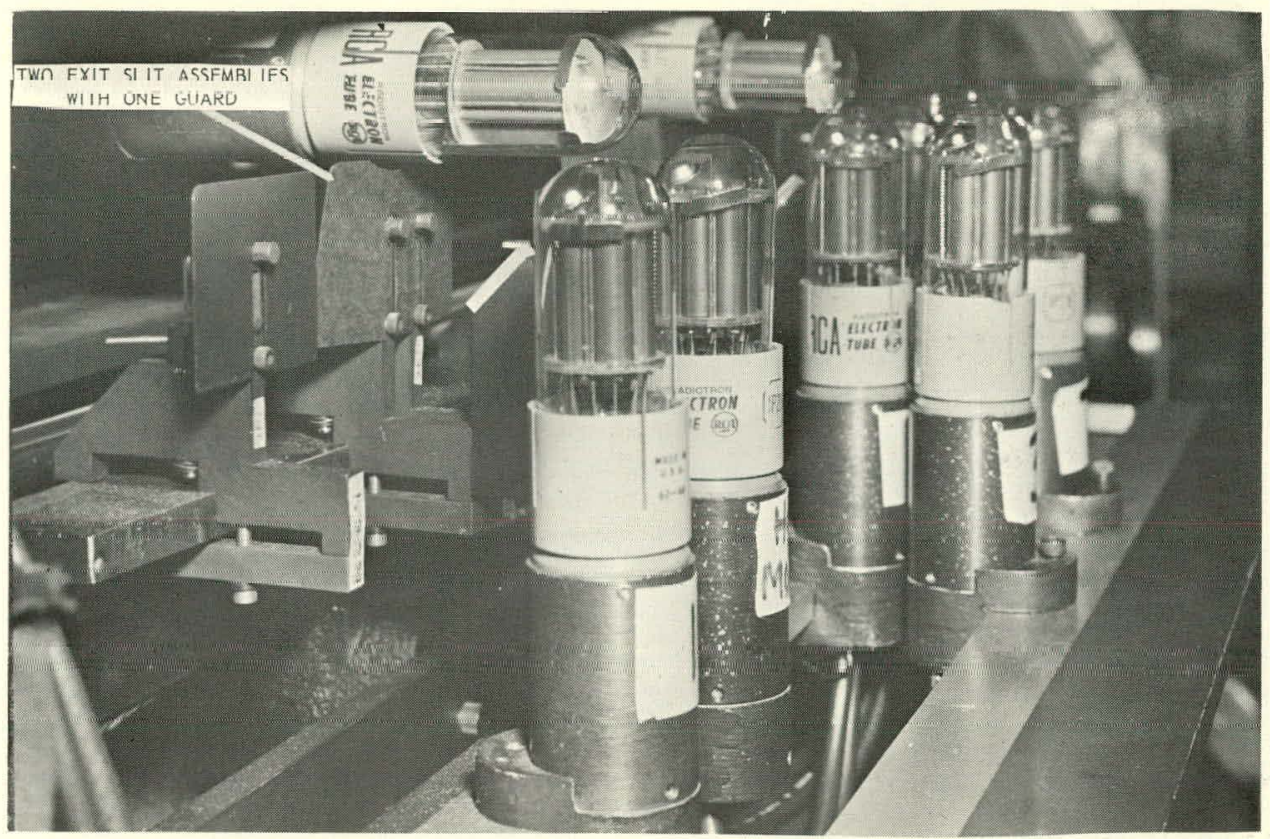

Figure 3- Photomultiplier Tubes and Exit Slits Mounted on Focal Curve

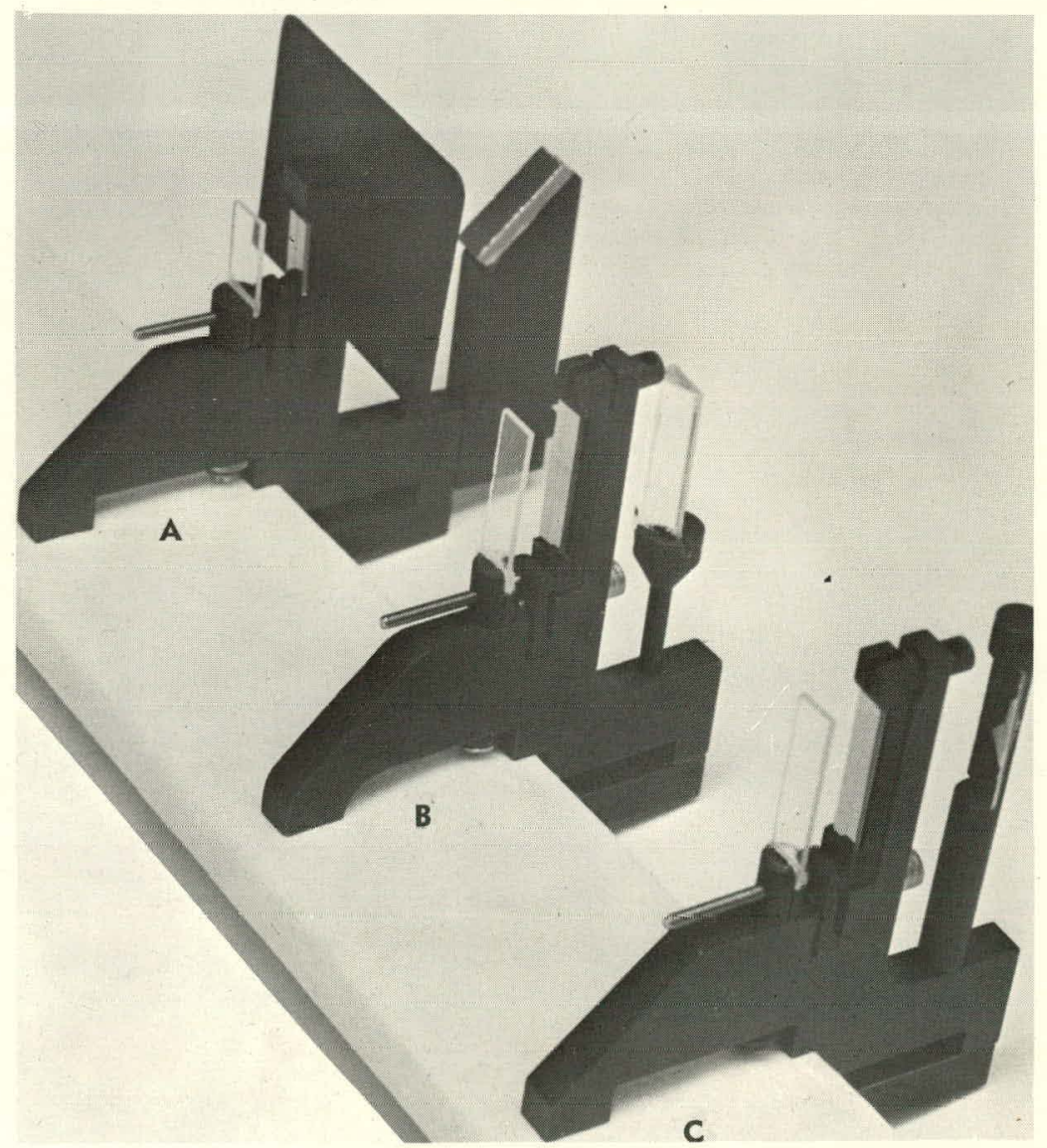

Figure 4 - Exit Slit Assemblies with ${ }^{7460}$ Prism and Mirrors for Diverting Light to Photomultiplier Tubes 


\section{RFP-644}

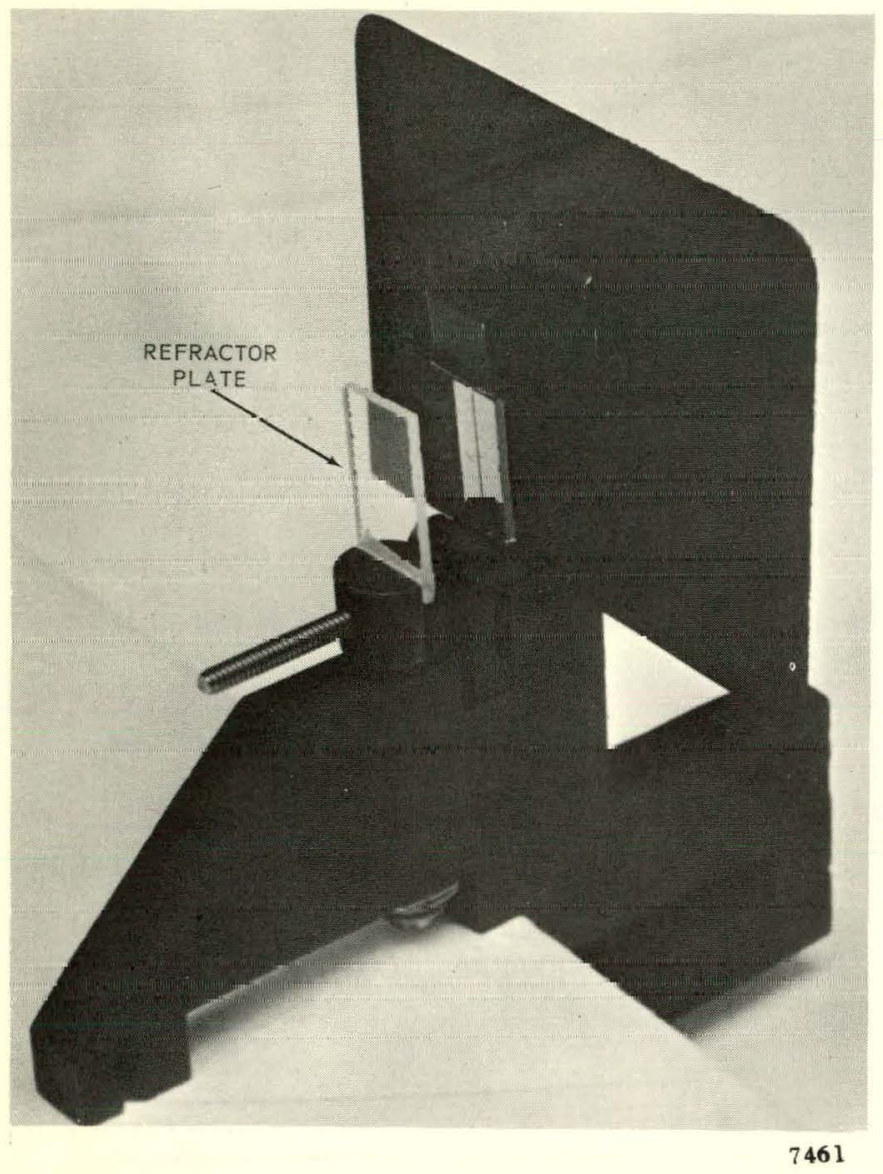

Figure 6 - Entrance Slit Assembly
Figure 5 - Exit Slit Assembly

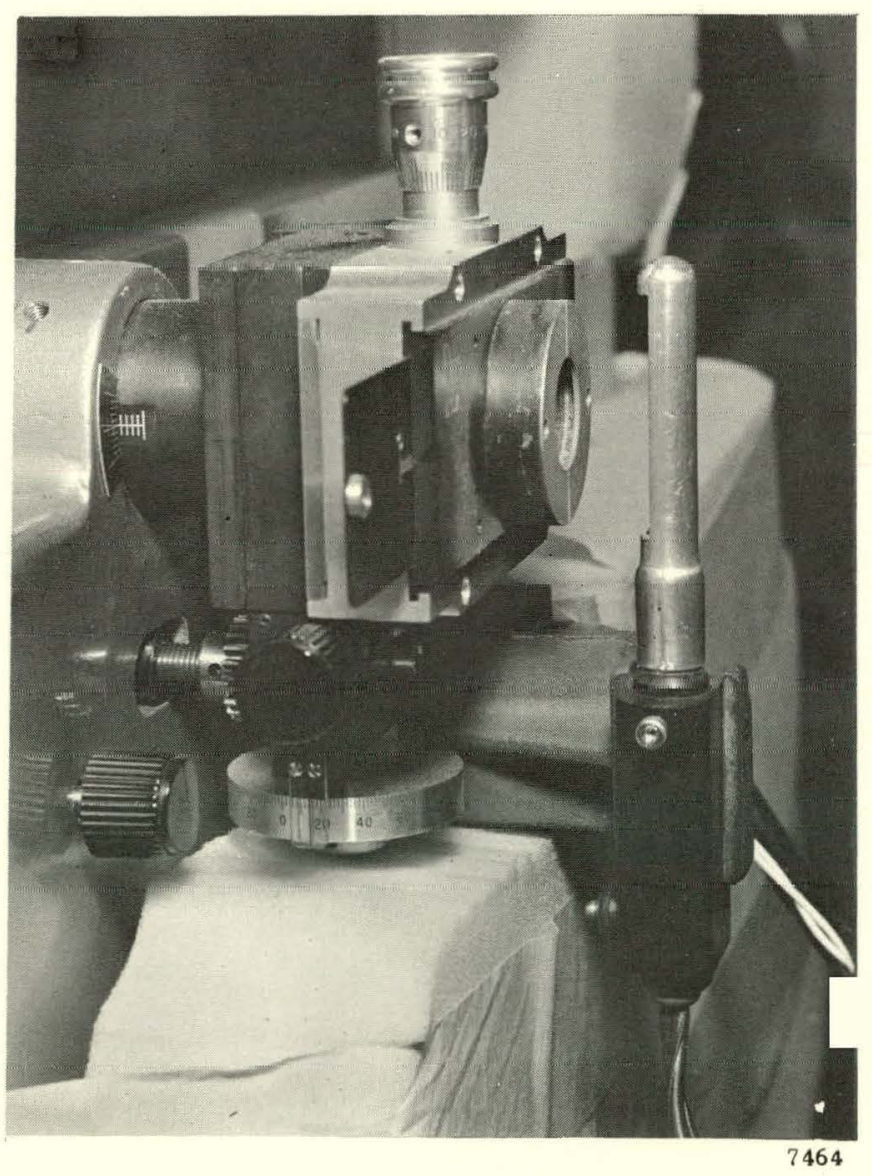



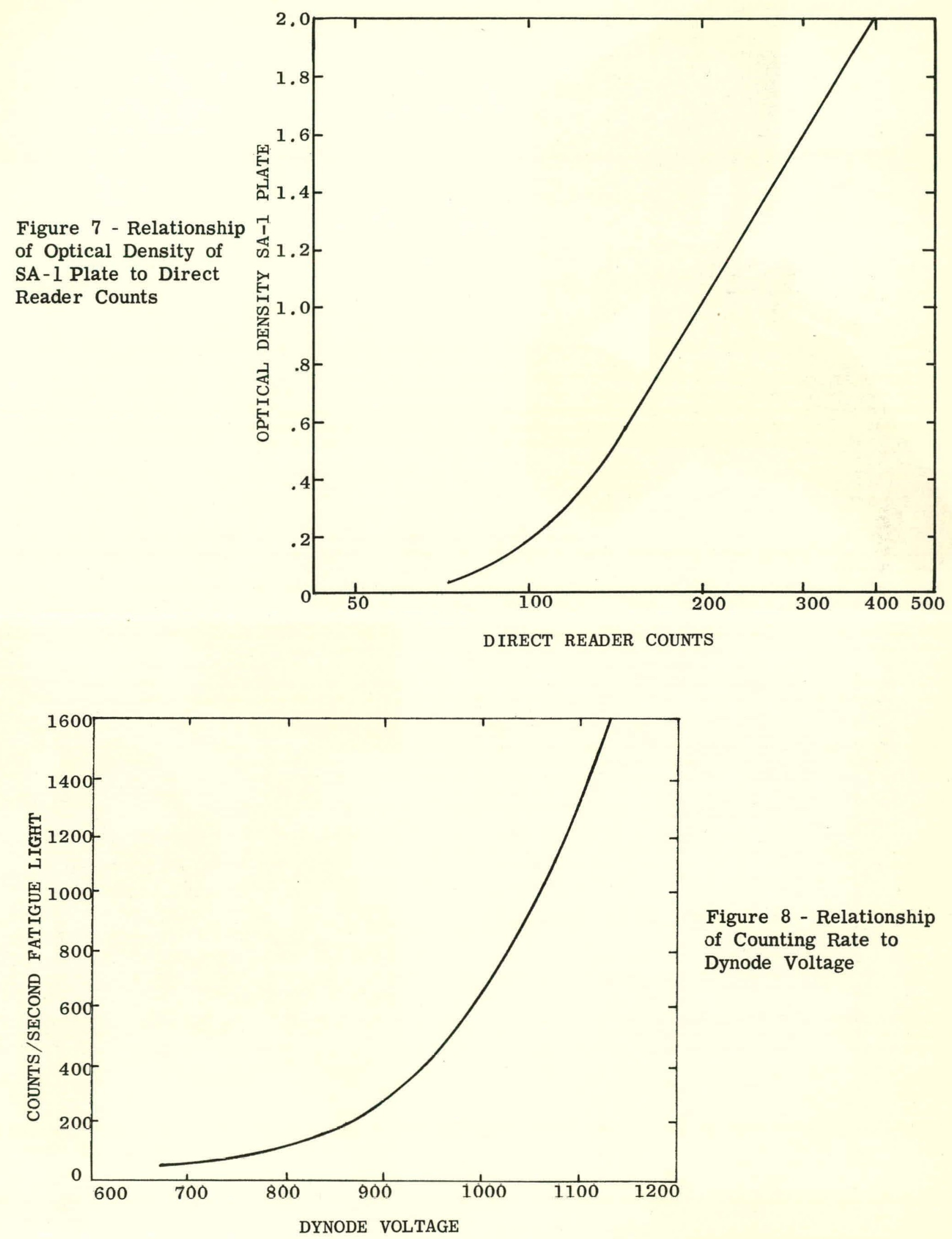

Figure 8 - Relationship of Counting Rate to Dynode Voltage 
Figure 9 - Relationship of Dark Current to Dynode Voltage
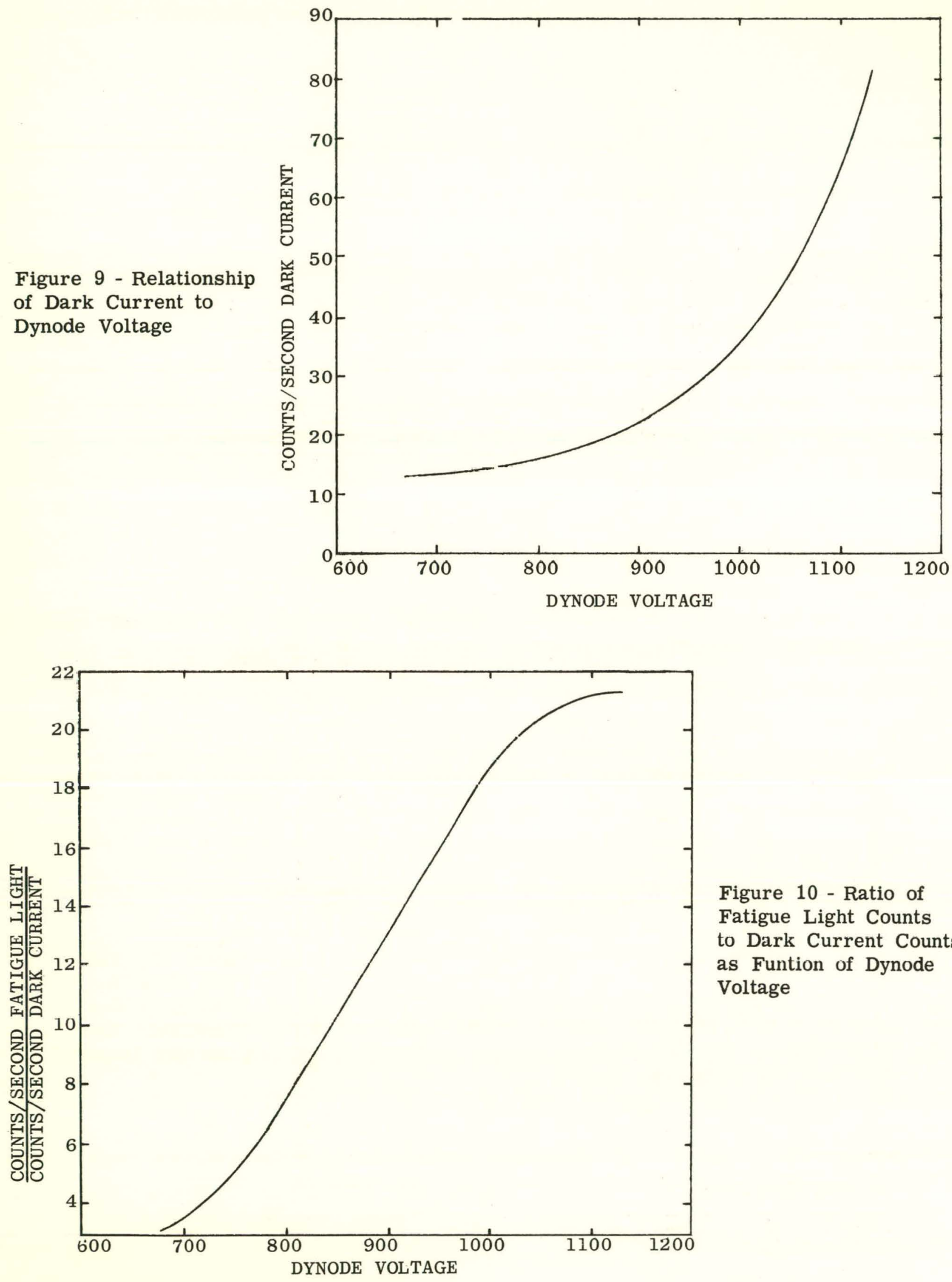

Figure 10 - Ratio of Fatigue Light Counts to Dark Current Counts as Funtion of Dynode Voltage 
Figure 11 - Relationship of Dynode Voltage to Voltage Control Setting
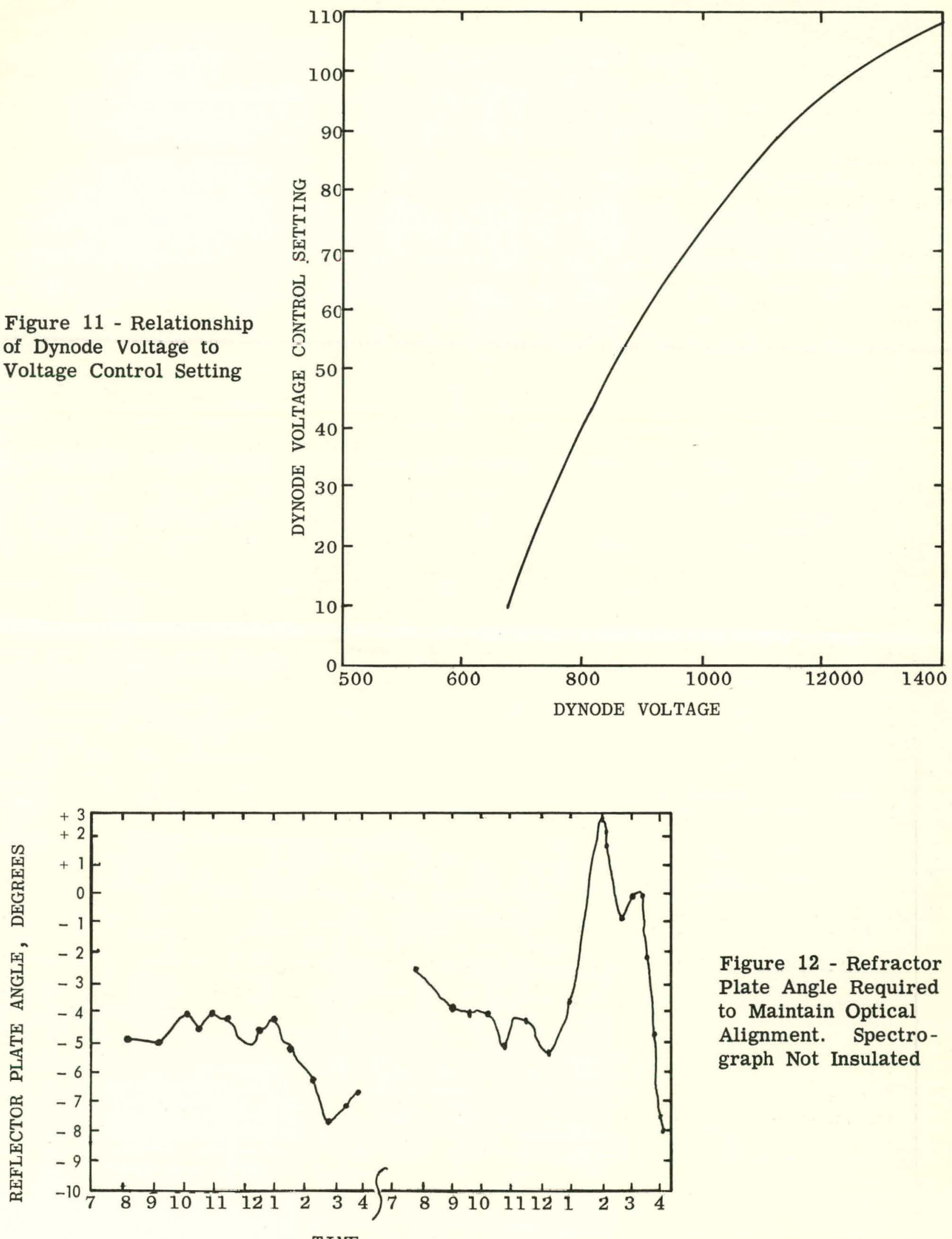

Figure 12 - Refractor Plate Angle Required to Maintain Optical Alignment. Spectrograph Not Insulated

T I ME 
Figure 13 - Displacement of Light (2536 $\AA$ ) by $0.87 \mathrm{~mm}$ Quartz Refractor Plate
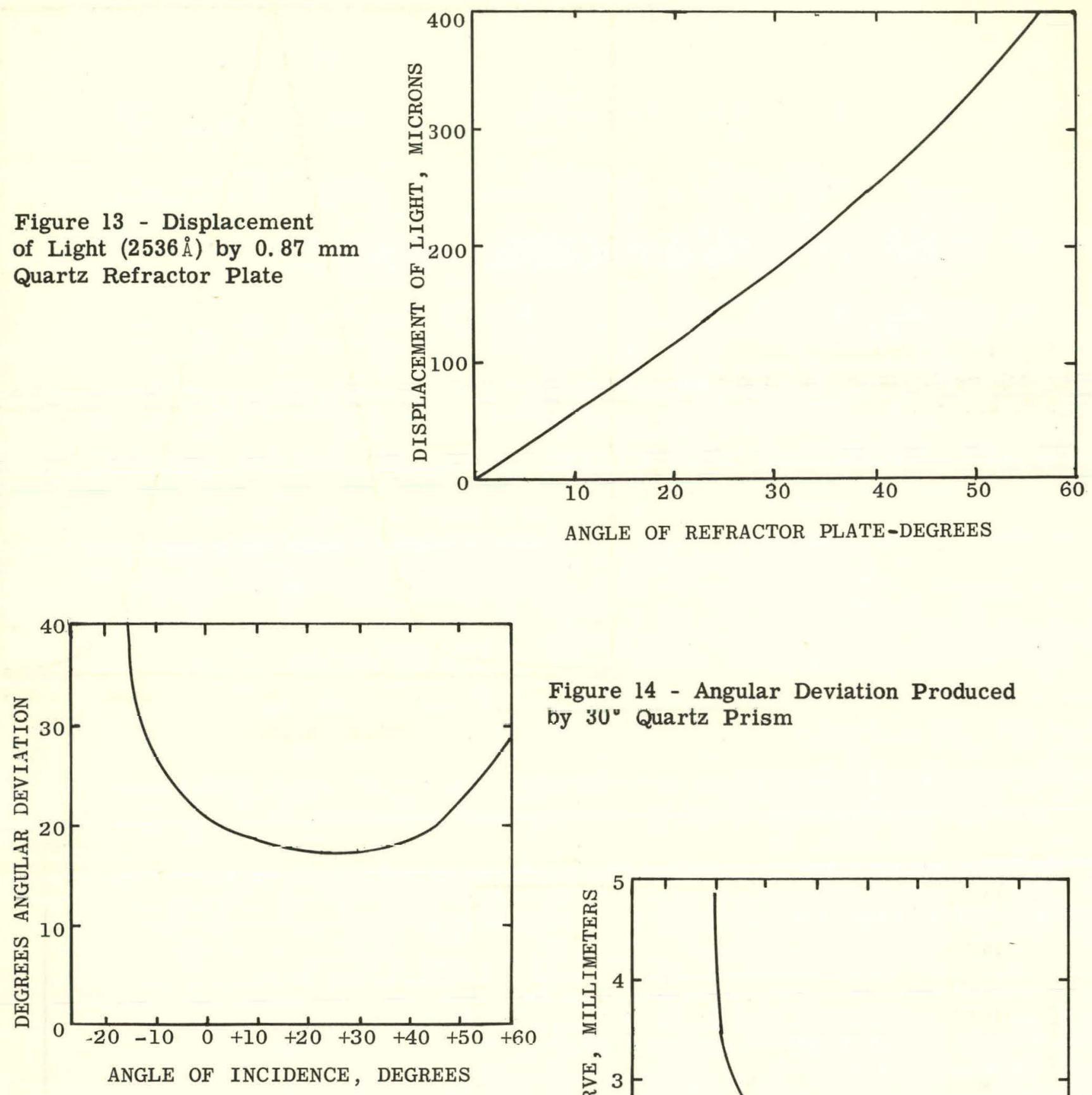

Figure 14 - Angular Deviation Produced by $30^{\circ}$ Quartz Prism

Figure 15 - Displacement at Focal Curve Produced by $30^{\circ}$ Quartz Prism

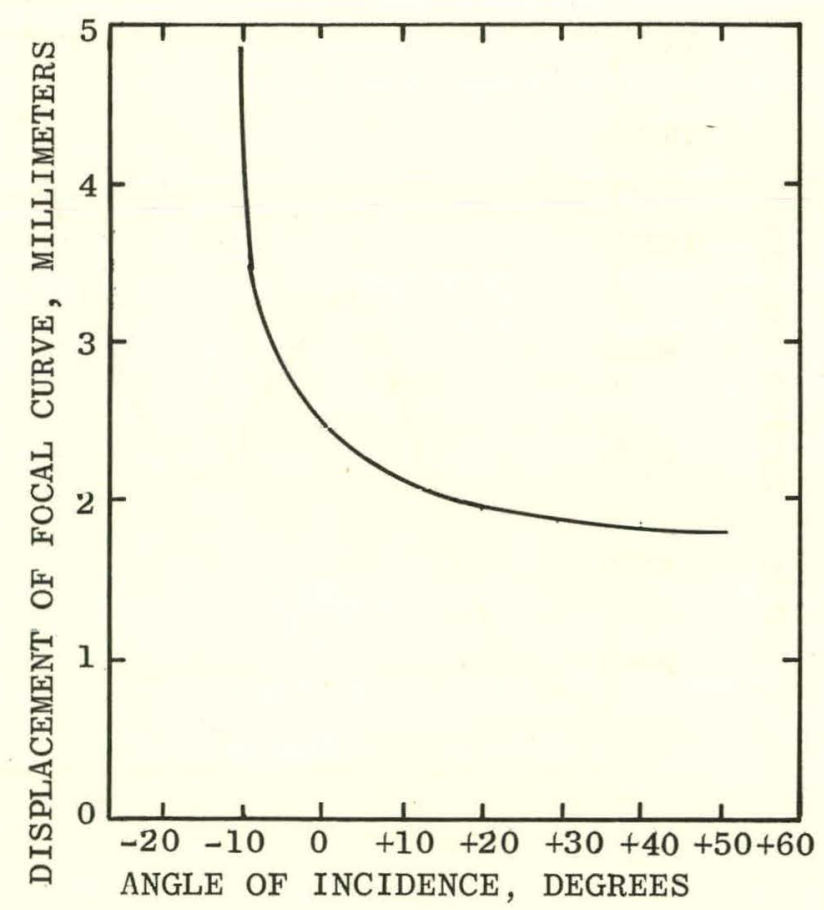


Figure' 16 - Profile of $2536 \AA$ Line, Hg Lamp $30 \mu$ Entrance Slit, $50 \mu$ Exit Slit
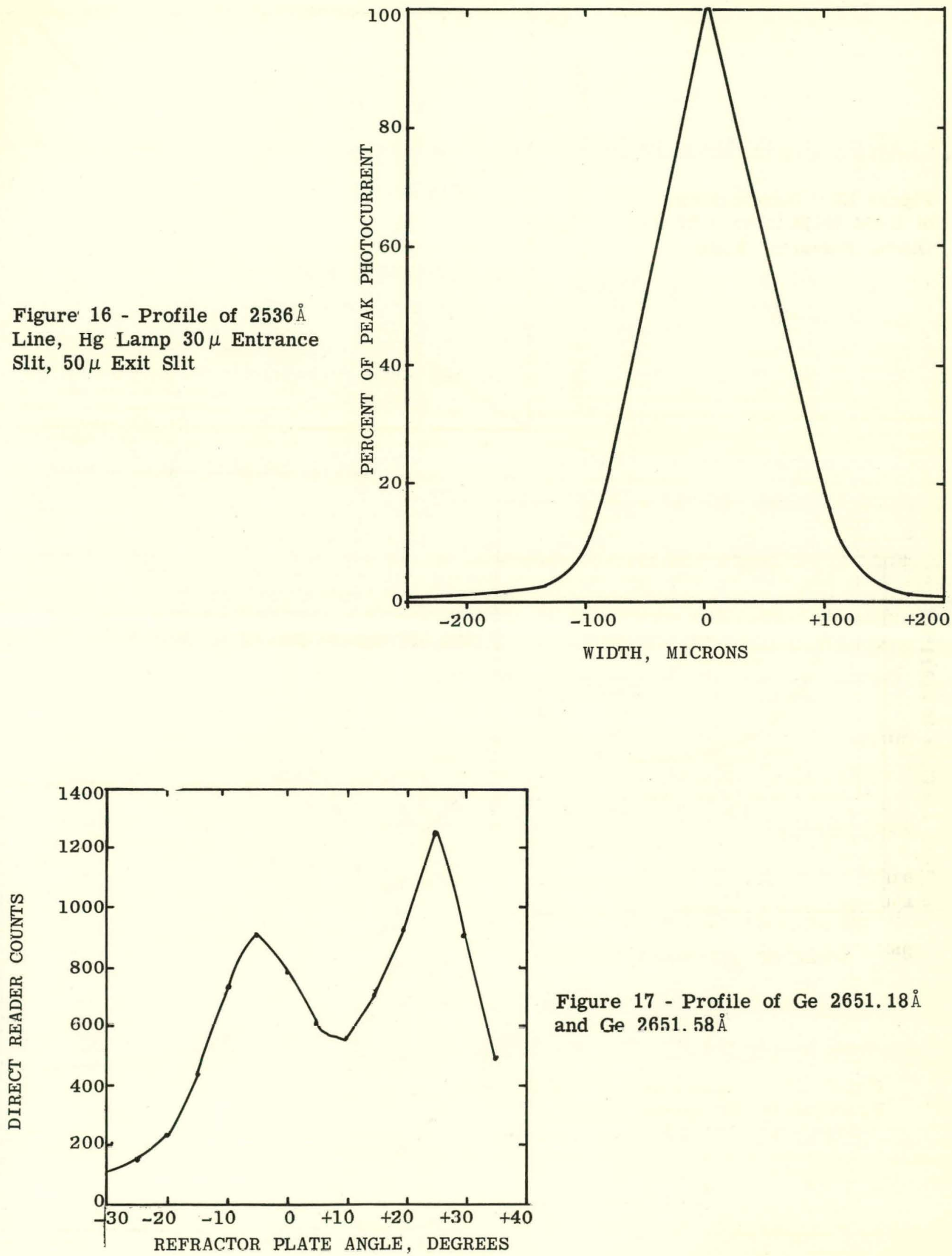

Figure 17 - Profile of Ge 2651.18 and $\mathrm{Ge} 2651.58 \AA$ 

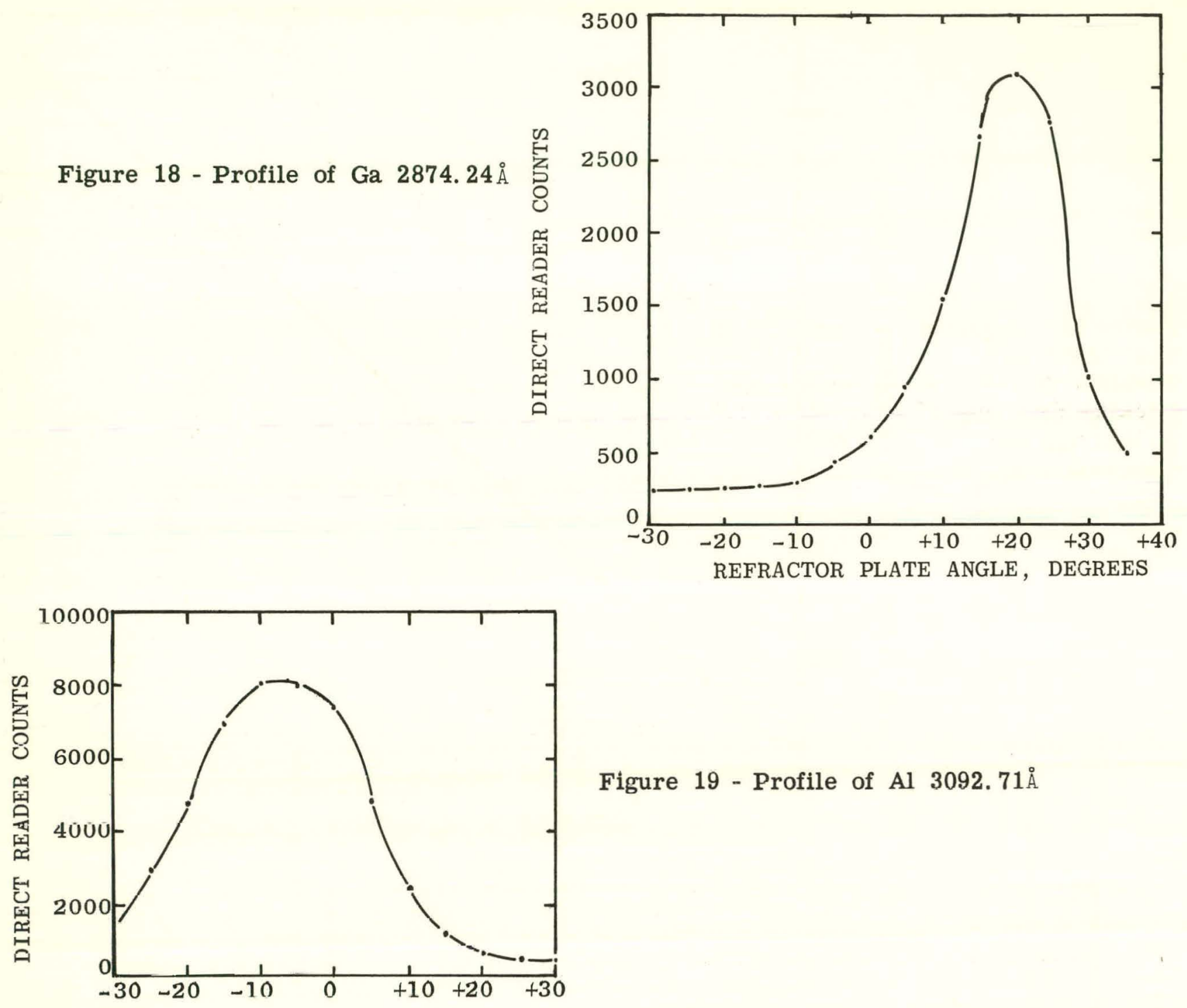

Figure 19 - Profile of Al $3092.71 \AA$

REFRACTOR PLATE ANGLE, DEGREES

Figure 20 - Profile of Ga 2874.24

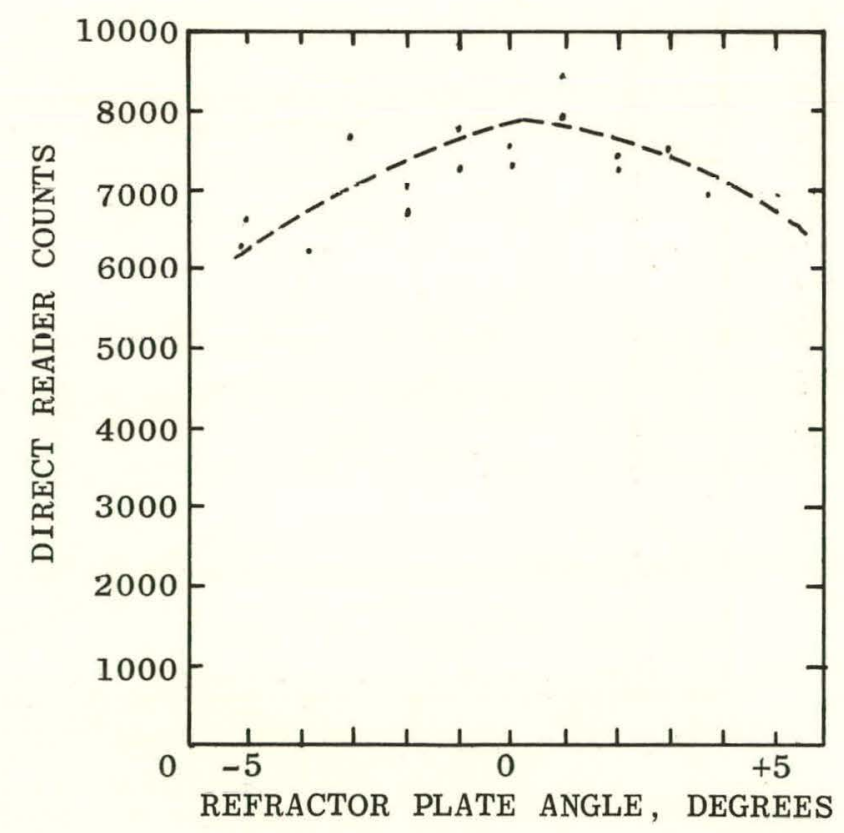



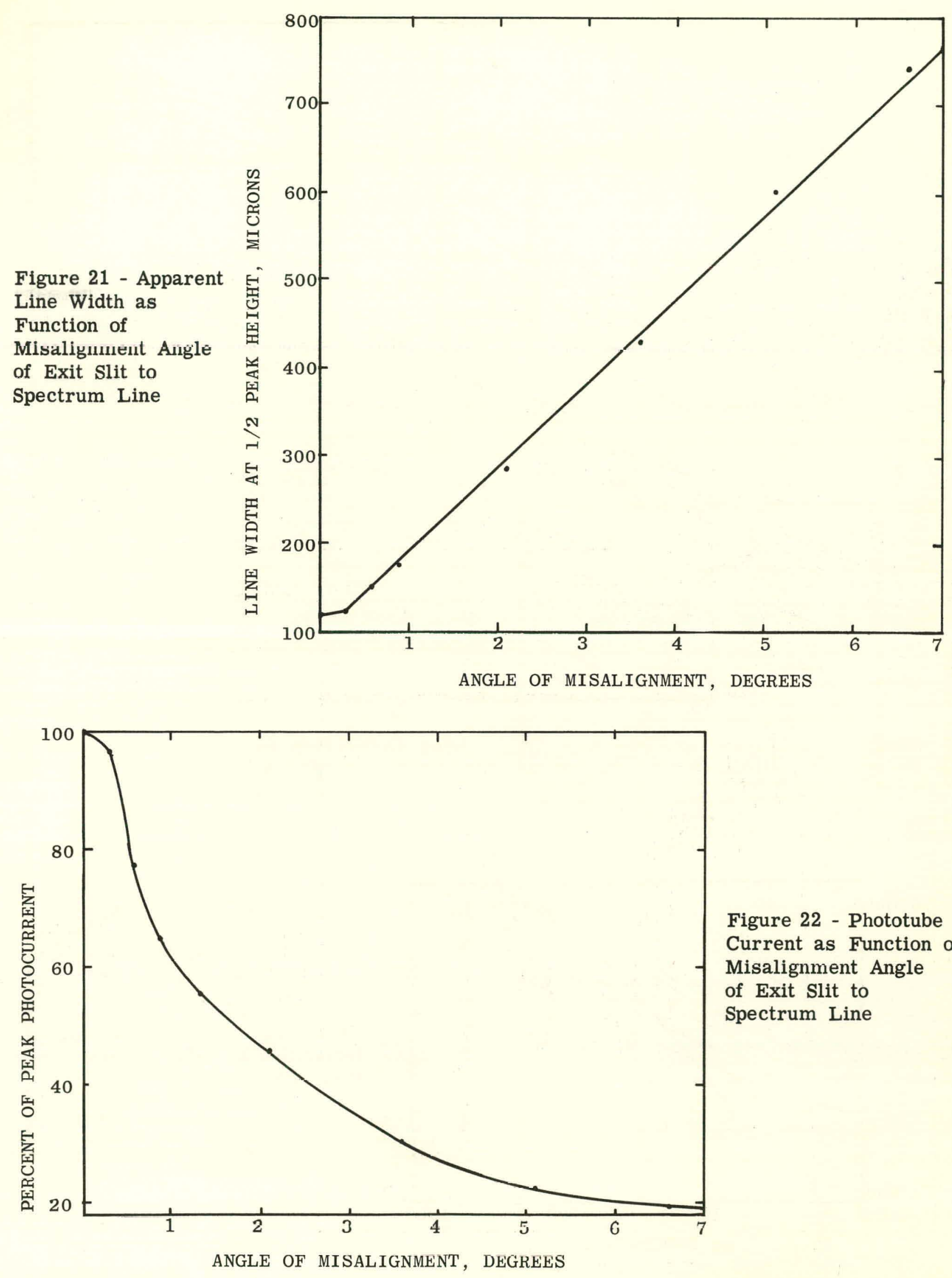

Figure 22 - Phototube Current as Function of Misalignment Angle of Exit Slit to Spectrum Line 
Figure 23 - Time-Intensity Curve, Ten Percent $\mathrm{FeO}$ in Graphite, Direct Current Arc, Fe $3020 \AA$
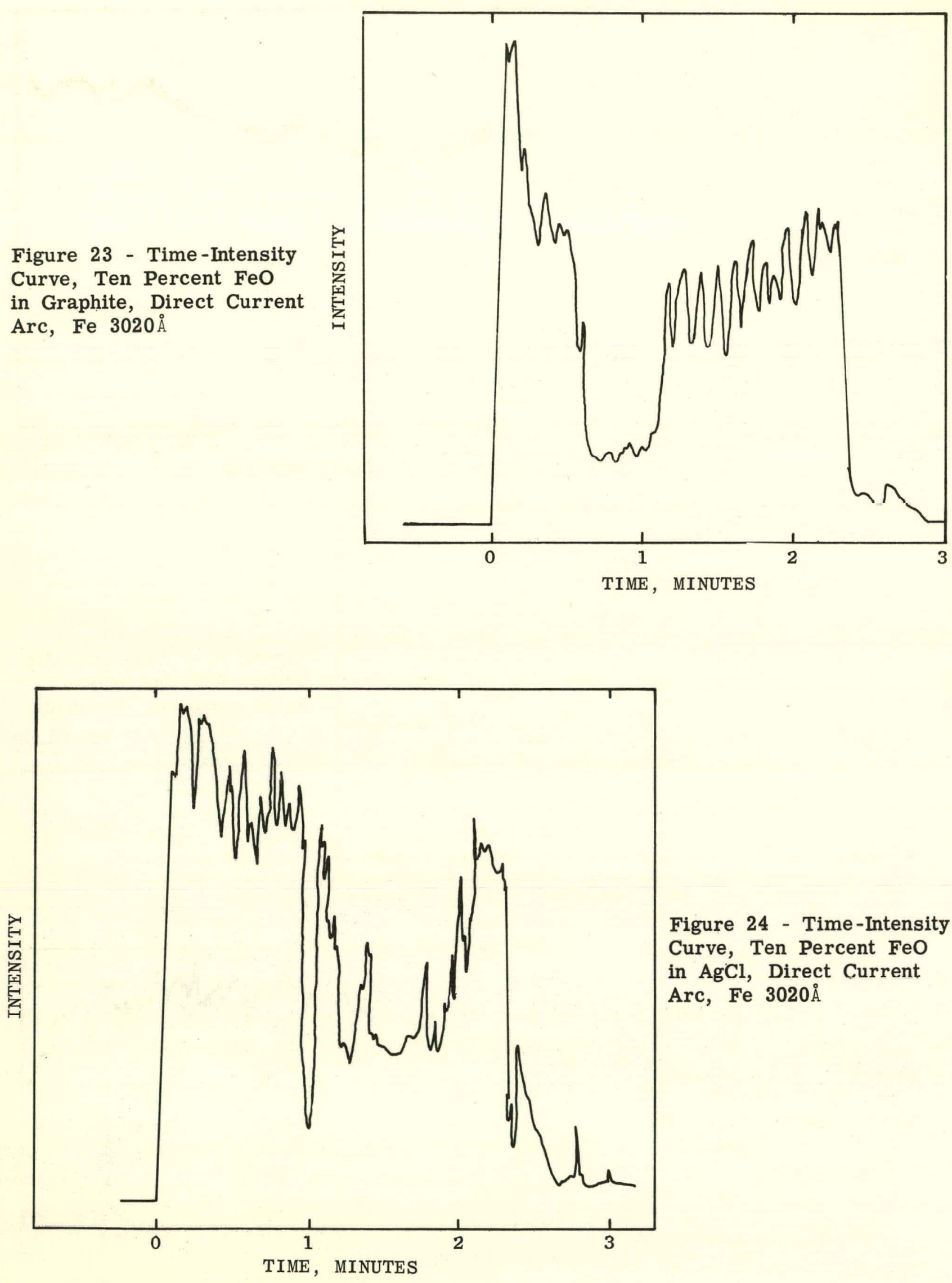

Figure 24 - Time-Intensity Curve, Ten Percent FeO in $\mathrm{AgCl}$, Direct Current Arc, Fe $3020 \AA$ 
Figure 25 - Time-Intensity Curve, Fe Rod, Sparked, Fe $3020 \AA$
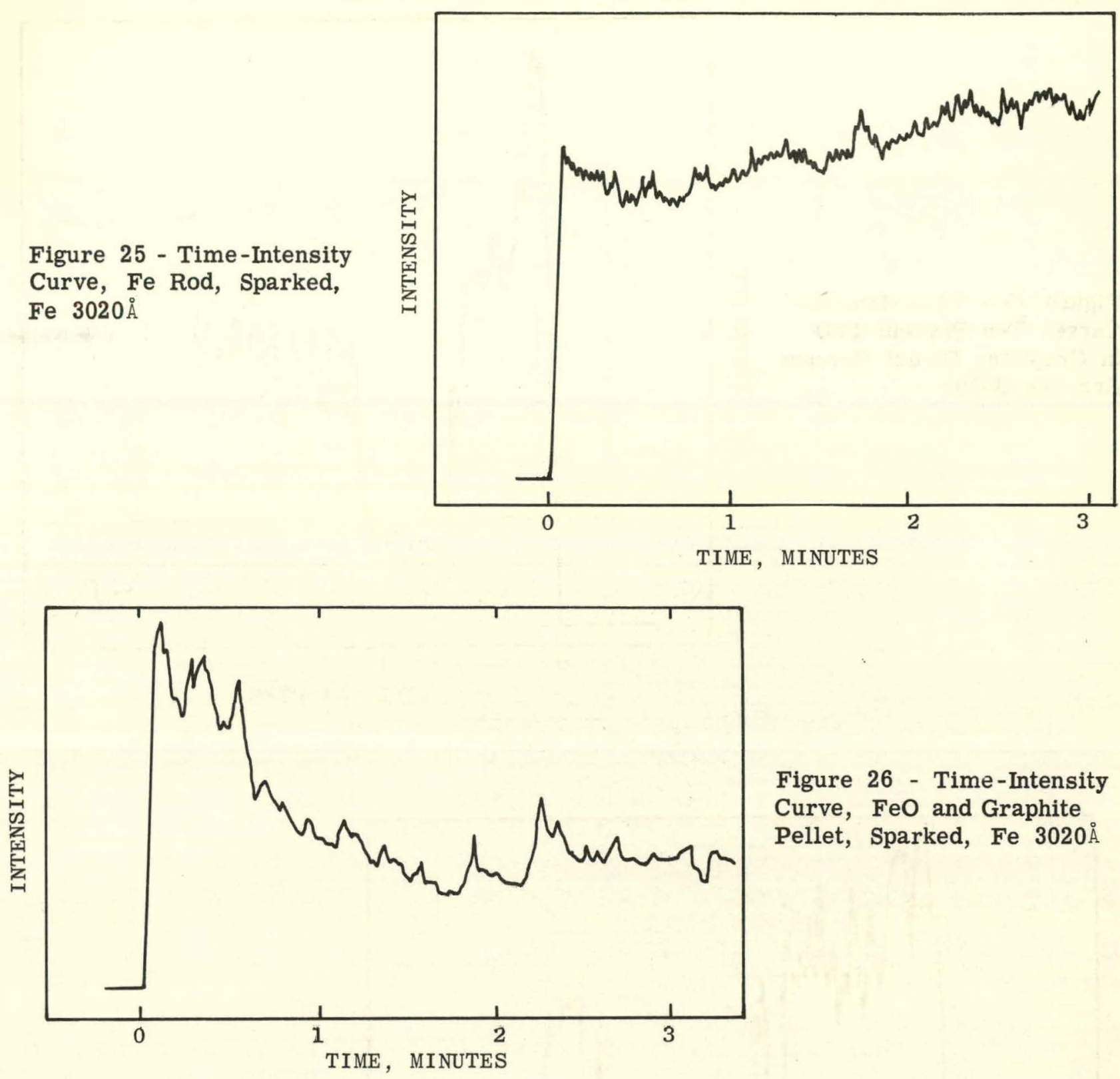

Figure 26 - Time-Intensity Curve, $\mathrm{FeO}$ and Graphite Pellet, Sparked, Fe $3020 \AA$

Figure 27 - Time-Intensity Curve, Ferric Nitrate, Rotrode, Sparked, Fe $3020 \AA$

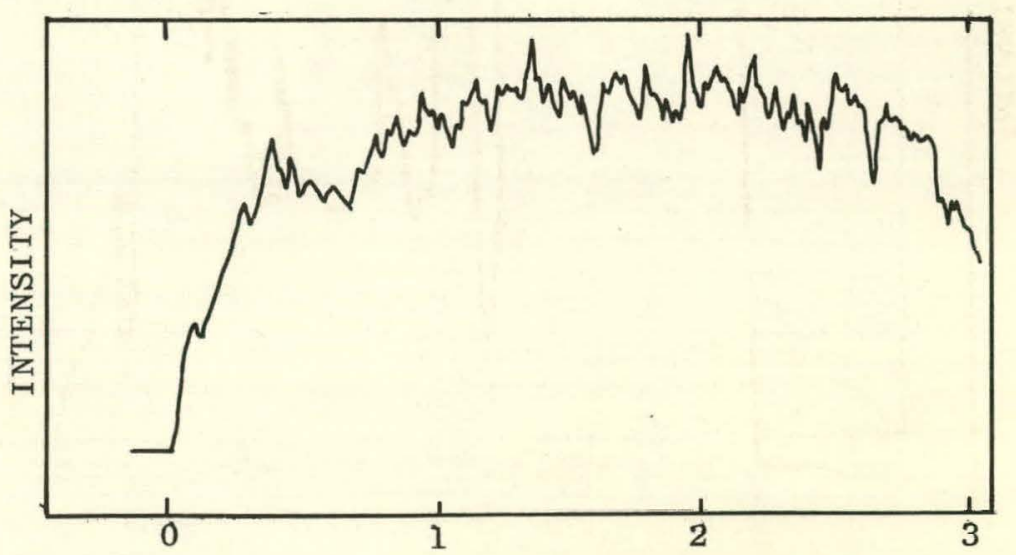

TIME, MINUTES 
Figure 28 - Time-Intensity Curve, Sparked, Fe $3020 \AA$ Electrodes Soaked in Ferric Nitrate Solution
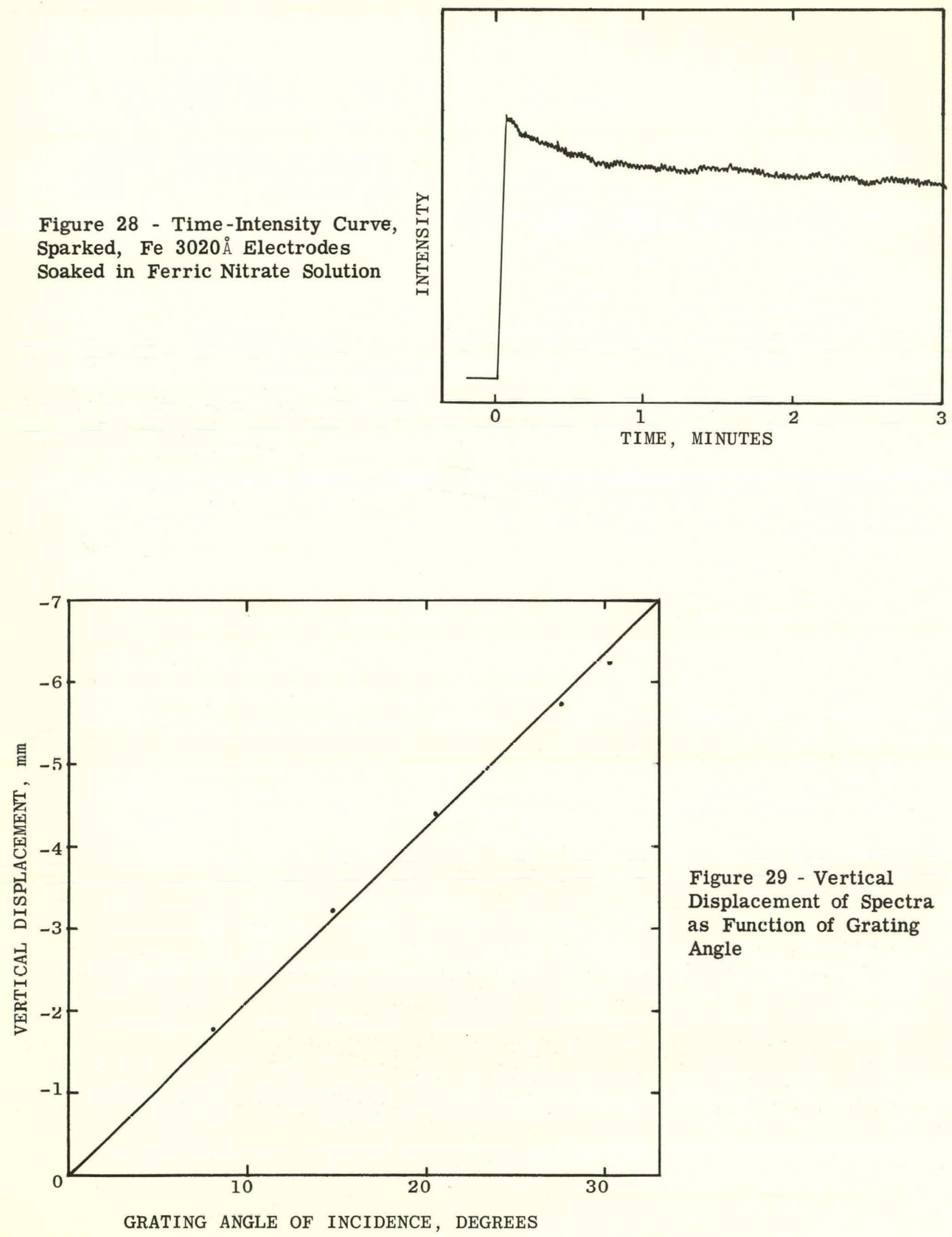

Figure 29 - Vertical Displacement of Spectra as Function of Grating Angle 


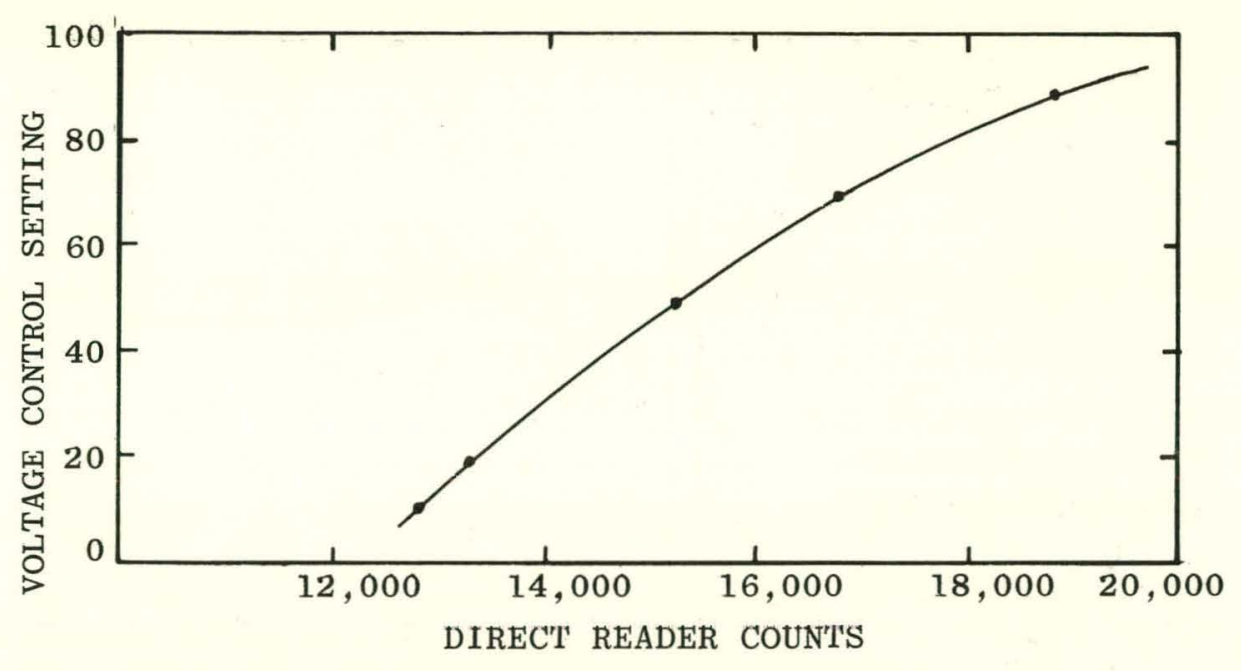

Figure 30 - Saturation Counts

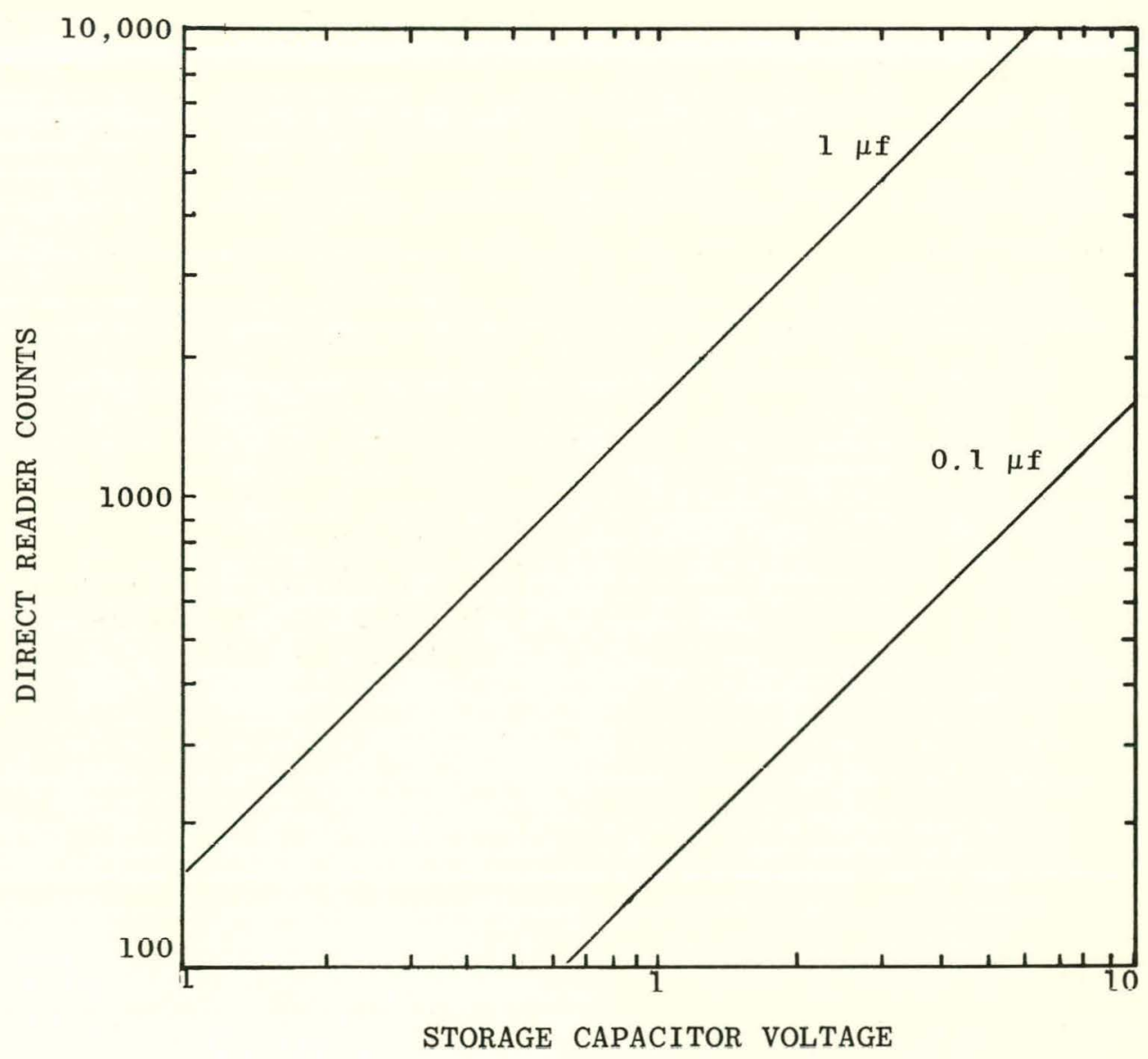

Figure 31 - Direct Reader Counts as Function of Capacitor Voltage 

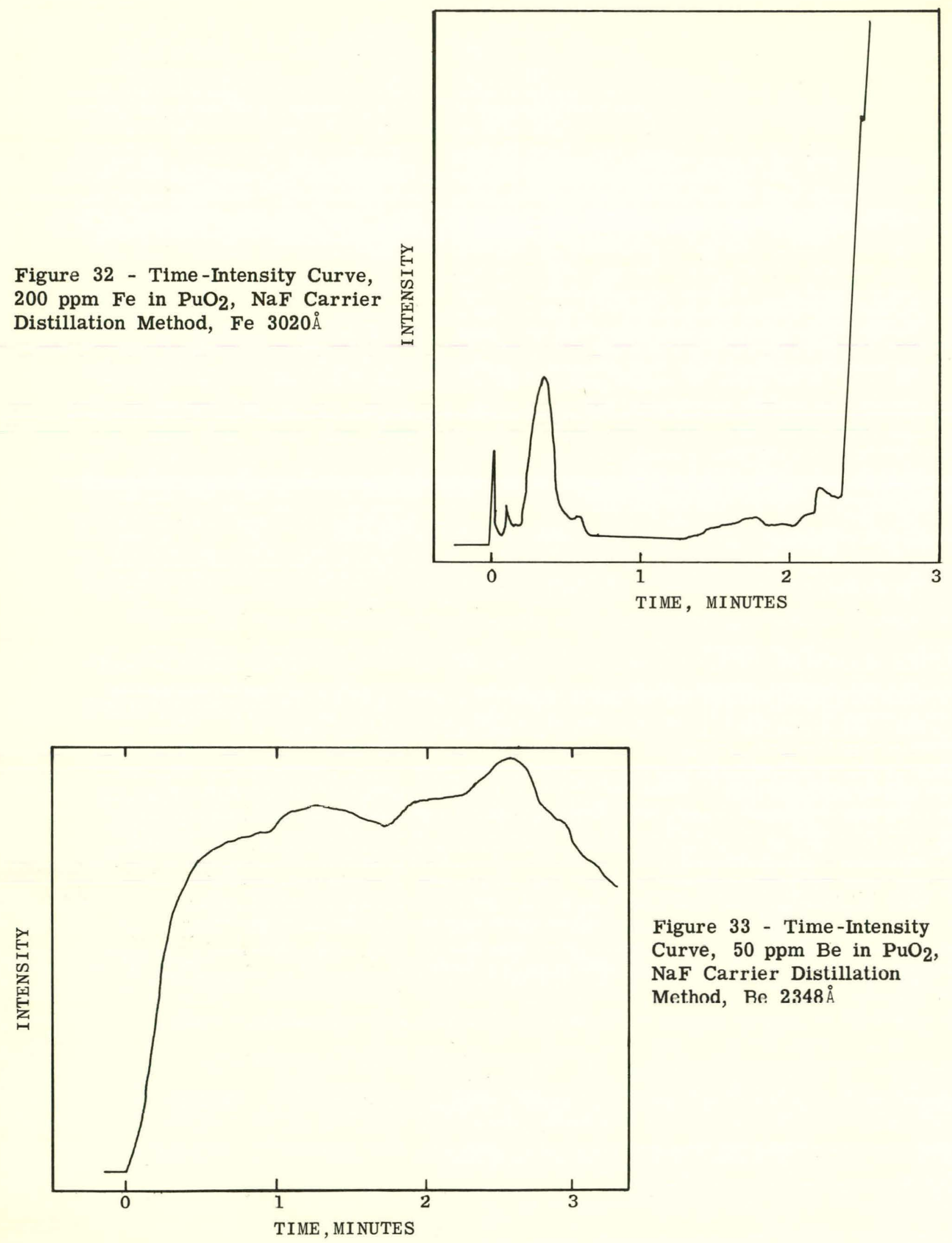

Figure 33 - Time-Intensity Curve, $50 \mathrm{ppm} \mathrm{Be}$ in $\mathrm{PuO}_{2}$, NaF Carrier Distillation Method, Re $2348 \AA$ 
Figure 34 - Time-Intensity Curve, $50 \mathrm{ppm} \mathrm{Cu}$ in $\mathrm{PuO}_{2}$, NaF Carrier Distillation Method, Cu $3247 \AA$
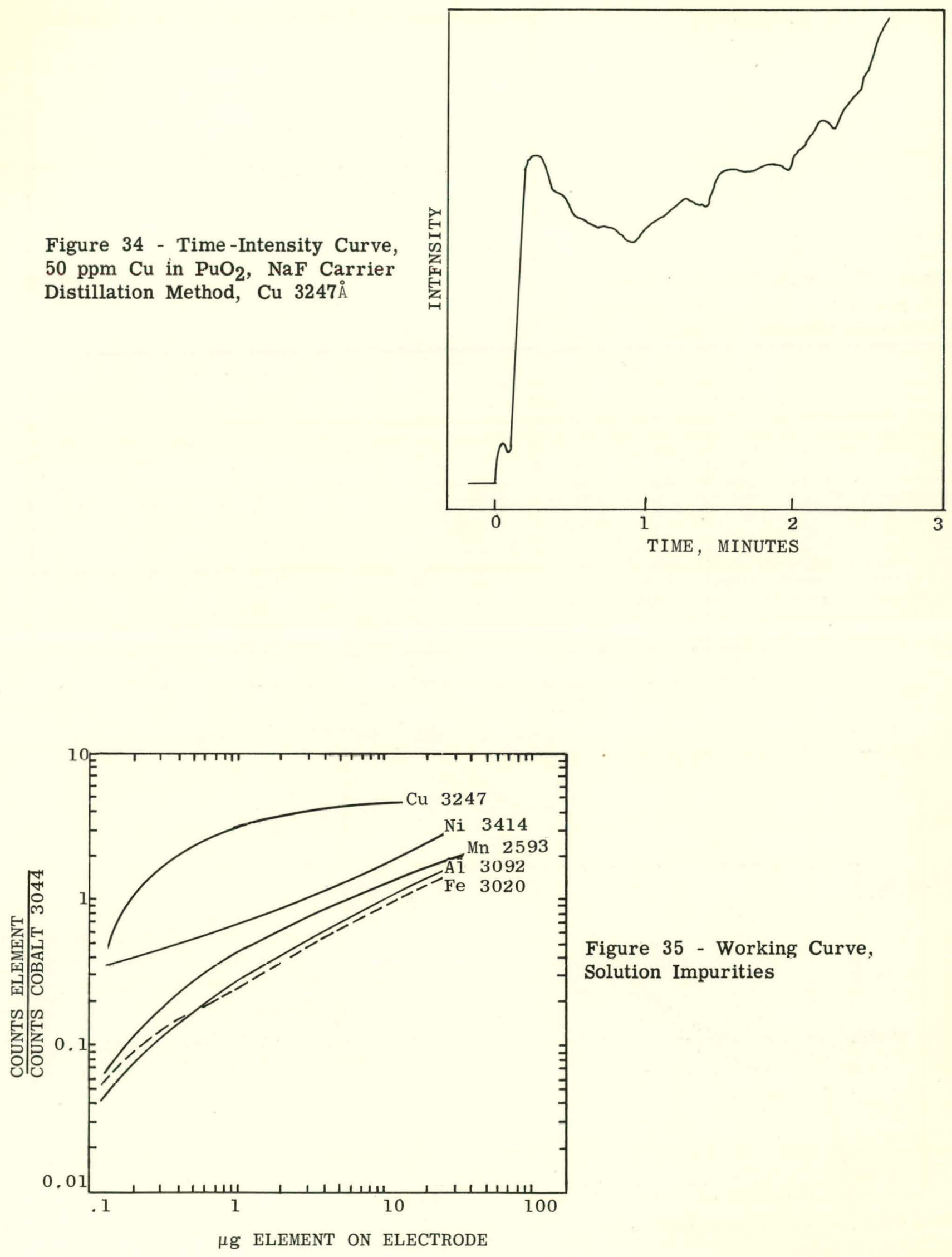

Figure 35 - Working Curve, Solution Impurities 

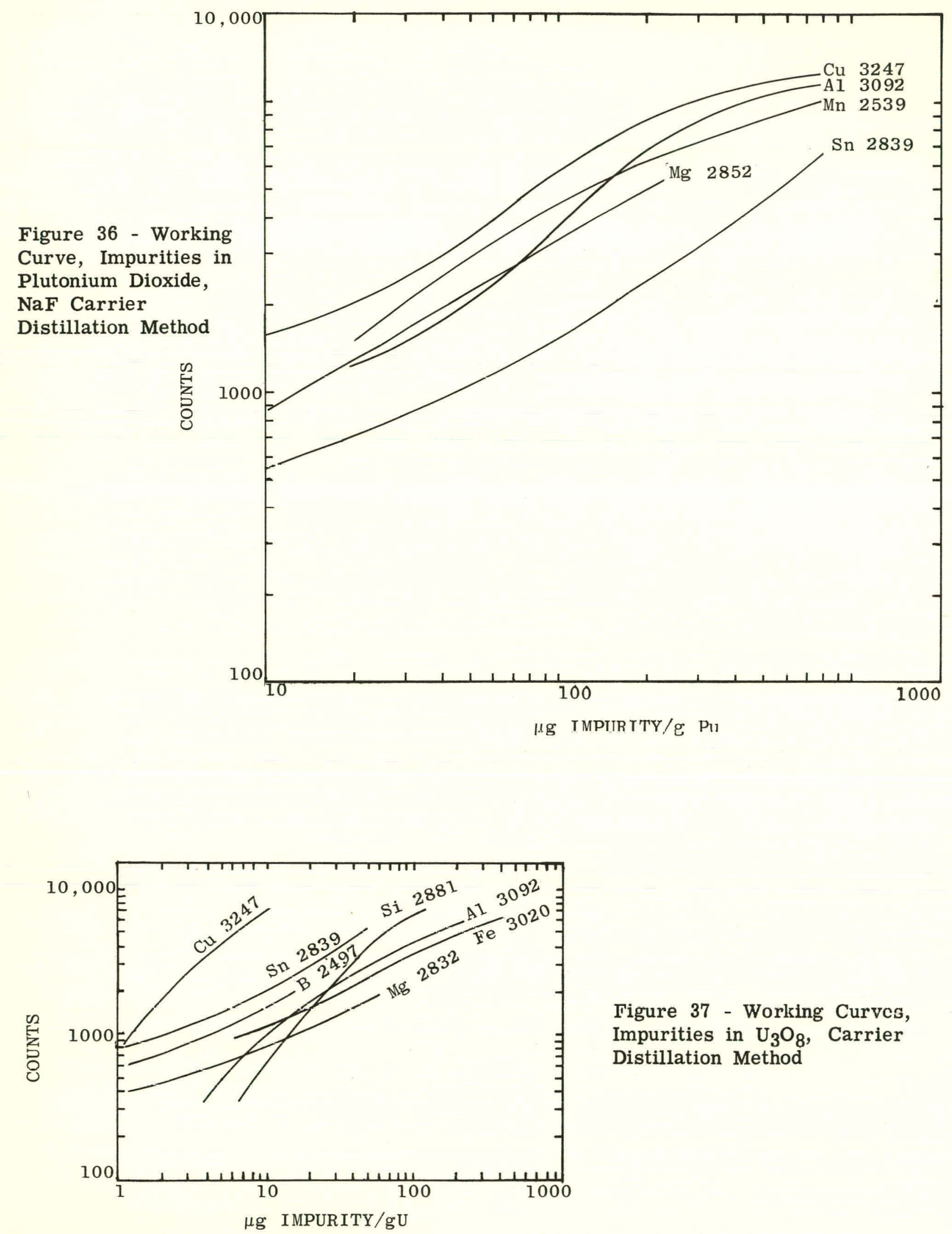

Figure 37 - Working Curves, Impurities in $\mathrm{U}_{3} \mathrm{O}_{8}$, Carrier Distillation Method 